\title{
Implications of Gut Microbiota in Neurodegenerative Diseases
}

\begin{abstract}
Haoming Zhang ${ }^{1 \dagger}$, Yijia Chen ${ }^{2 \dagger}$, Zifan Wang ${ }^{1}$, Gaijie Xie ${ }^{1}$, Mingming Liu ${ }^{3}$, Boyu Yuan ${ }^{4}$, Hongxia Chai ${ }^{1}$, Wei Wang ${ }^{1,3^{*}}$ and Ping Cheng ${ }^{1 *}$

1 Innovative Institute of Animal Healthy Breeding, College of Animal Sciences and Technology, Zhongkai University of Agriculture and Engineering, Guangzhou, China, ${ }^{2}$ School of Life Science, Fudan University, Shanghai, China, ${ }^{3}$ Key Laboratory of Zoonosis Research, Ministry of Education, Jilin University, Changchun, China, ${ }^{4}$ State Key Laboratory of Oncology in South China, Collaborative Innovation Center for Cancer Medicine, Sun Yat-sen University Cancer Center, Guangzhou, China
\end{abstract}

\section{OPEN ACCESS}

Edited by:

Pamela Ann McCombe,

The University of Queensland,

Australia

Reviewed by:

Vladimir Stanislavovich Rogovskii, Pirogov Russian National Research

Medical University, Russia

Erica Costantini,

University of Studies G. d'Annunzio

Chieti and Pescara, Italy

*Correspondence:

Wei Wang

wang_wei99@jlu.edu.cn

Ping Cheng

nkpcheng@163.com

tThese authors have contributed equally to this work

Specialty section:

This article was submitted to

Multiple Sclerosis

and Neuroimmunology,

a section of the journal

Frontiers in Immunology

Received: 29 September 2021 Accepted: 19 January 2022 Published: 14 February 2022

Citation:

Zhang H, Chen Y, Wang Z, Xie G, Liu M, Yuan B, Chai $H$,

Wang $W$ and Cheng $P$ (2022)

Implications of Gut Microbiota in

Neurodegenerative Diseases.

Front. Immunol. 13:785644. doi: 10.3389/fimmu.2022.785644
The morbidity associated with neurodegenerative diseases (NDs) is increasing, posing a threat to the mental and physical quality of life of humans. The crucial effect of microbiota on brain physiological processes is mediated through a bidirectional interaction, termed as the gut-brain axis (GBA), which is being investigated in studies. Many clinical and laboratory trials have indicated the importance of microbiota in the development of NDs via various microbial molecules that transmit from the gut to the brain across the GBA or nervous system. In this review, we summarize the implications of gut microbiota in ND, which will be beneficial for understanding the etiology and progression of NDs that may in turn help in developing ND interventions and clinical treatments for these diseases.

Keywords: gut microbiota, neurodegenerative diseases, gut-brain axis, blood-brain barrier, microbial molecules

\section{INTRODUCTION}

Neurodegenerative diseases (NDs) including Alzheimer's disease (AD), Parkinson's disease (PD), Huntingdon disease (HD), and multiple sclerosis (MS) are characterized by the progressive loss of neurons that is associated with neurotoxic etiological substances in the brain and the surrounding organs. The maximum human life span has expanded because of the improvement in nutrition and health care with the development of the economy and technology. However, the incidence of NDs increases with age, generating increasingly severe burdens to society $(1,2)$. Unfortunately, because of the unclear pathogenesis of these diseases and the complexity of the nervous system, an effective treatment is lacking, although several clinical trials are ongoing.

Diverse microbes including bacteria, archaea, viruses, and various eukaryotes such as fungi and protozoa are present in different ecological niches in the gut and are collectively known as the gut microbiota (3). The gut microbiota profoundly affects several aspects of host physiology, including nutritional metabolism, anti-infection, immune system, and nerve development $(4,5)$. Rapid industrialization, urbanization, and development in food and medical technology, such as increasing intake of fast food, cause the gut microbiota to confront a different habitat, and thus, it has become more vulnerable than before (6). Recently, the importance of gut microbiota has emerged because of its vital role in NDs and in modulating the differentiation, maturation, proliferation, and activation of tissue-resident immune cells in the central nervous system (CNS) (7-11). 
Gut-brain axis (GBA) participates in the bidirectional communication between the gut and the brain via neurotransmitters and various metabolites $(12,13)$. In this review, we summarize the possible pathophysiological roles of the microbiota in NDs. Furthermore, we focus on the potential of microbiota composition and metabolites as novel therapeutic interventions for these chronic diseases.

\subsection{Gut Microbiota}

Gut microbiota that consists of various dynamic microorganisms establishes a symbiotic relationship with the host. The metabolic activities and interactions of gut microbiota affect normal physiology and susceptibility of the host to diseases $(5,14)$. The differences in $\mathrm{pH}$, immune factors, and digestive enzymes in the gut are responsible for the diversity and individual differences at the bacterial strain level (15). Moreover, each individual harbors distinct microbial community that results in the formation of a stable and resilient state (14). In an adult gut mucosa, Bacteroidetes and Firmicutes are the predominant phyla, whereas the abundance of Actinobacteria, Proteobacteria, and Verrucomicrobia is low $(16,17)$.

Gut microbiota can directly affect human health by secreting microbial components such as vitamins, essential amino acids, and lipids $(9,13,18)$. These components may be involved in the GBA via neural, endocrine, and immune signaling pathways and thus affect physiological functions such as gastrointestinal barrier, nutritional metabolism, immune response, and neurological development associated with aging (19-22).

\subsection{Correlation Between Gut Microbiota and Neurodegenerative Disease}

The gut microbiota is considered essential for brain physiological processes such as myelination, neurogenesis, and microglial activation; regulation of human behavior; and affecting mental processes such as mood and cognition $(9,23,24)$. Moreover, the gut microbiota is highly sensitive to external lifestyles such as diet, sleep deprivation, circadian rhythm disturbances, chronic noise, and sedentary behavior, which are also considered the risk factors for some NDs $(6,25-31)$. The gut microbiota is critical for maintaining a healthy functional state of microglia, which is necessary to prevent neurodevelopmental abnormalities and NDs (8, 32-34). Clinical trials have confirmed the crucial role of microglia activation in $\mathrm{AD}$ pathology $(22,35,36)$.

\subsection{Gut Microbiota-Brain Communications}

\subsubsection{Gut-Brain Axis}

GBA refers to the communication between gut microbiota and the brain and involves multiple physiological processes, which are strategic points in maintaining the homeostasis of the gastrointestinal (GI) tract, CNS, and microbial systems (Figure 1).

The pathways comprise the vagus nerve and the neural, endocrine, and immune systems that exert direct or indirect effects by stimulating the release of chemical transmitters such as microbial hormones and metabolites $(37,38)$. Therefore, these systems involved in GBA regulate many functions, such as regulation of brain activity and emotions, immunomodulation, energy balance, and activation (39-41). The microbiota as a link between mental health, cognitive brain centers, and peripheral intestinal function has garnered considerable scientific attention. Studies have reported that the disruption of GBA may be associated with mood disorders and dysbiosis of gut microbiota $(40,42)$, and the microbiota may affect the anxiety and depressive behavior via the GBA (43). Depending on the disease severity, specific microbiota alterations are found in autistic patients (44).

\subsubsection{Blood-Brain Barrier and Gut-Derived Molecules}

The blood-brain barrier (BBB) is an anatomical, functional structure that separates blood from brain tissues and cerebrospinal fluid; it is composed of pia mater, choroid plexus, cerebrovascular, and astrocytes (45-47). The BBB serves as a gateway for the passage of many crucial substances required for CNS functioning and secretes substances into the blood and brain that are crucial for maintaining the CNS homeostasis. Moreover, the $\mathrm{BBB}$ could also limit the transport of gut-derived molecules into the brain (48). Vulnerable BBB is caused by aging and may induce cerebrovascular inflammation and CNS disorder (49-52).

For example, microorganism-associated molecular patterns (MAMPs) play critical roles in the structural integrity and essential cellular functions in microorganisms (53). When MAMPs are accidentally enhanced or decreased, acute or chronic inflammation associated with various neurological disorders is induced (54).

Several microbial molecules such as lipopolysaccharides (LPS), short-chain fatty acids (SCFAs), trimethylamines (TMAs), and vitamins are associated with the permeability of BBB (55-57). These molecules could act on BBB to directly affect brain neurons or stimulate the immune and endocrine systems to protect against neuroinflammation or neurodegeneration.

LPS is a crucial component of the outer membrane of Gramnegative bacteria. It is one of the most extensively studied components of bacterial immune stimulation, which can induce systemic inflammation and sepsis when it is present in an excessive amount (58). The permeability of BBB in germ-free mice decreased after LPS administration (56). In addition, a study reported that systemic LPS can stimulate the microglia, resulting in chronic neuroinflammation in germ-free mice (59). Moreover, indigestible diet fibers and resistant starch can be fermented by gut microbiota, producing SCFAs (such as acetate, propionate, and butyrate) and other metabolites such as hydrogen and methane (60). SCFAs affect the psychological functions and suppress inflammation by affecting cellular functions including G-protein-coupled receptor activation and histone deacetylase activation, which further affect host intestinal epithelial integrity, BBB integrity, and brain functions (61-63). The gut-derived TMA, namely, trimethylamine-n-oxide (TMAO), is secreted by microbiomes such as Anaerococcus, Clostridium, Desulfovibrio, and Providencia (64). The presence of TMAO in cerebrospinal fluid revealed its ability to cross the BBB (65). Interestingly, in a clinical study, the TMAO levels in the cerebrospinal fluid increased in cognitively impaired individuals with $\mathrm{AD}$, representing a finding that may be useful 


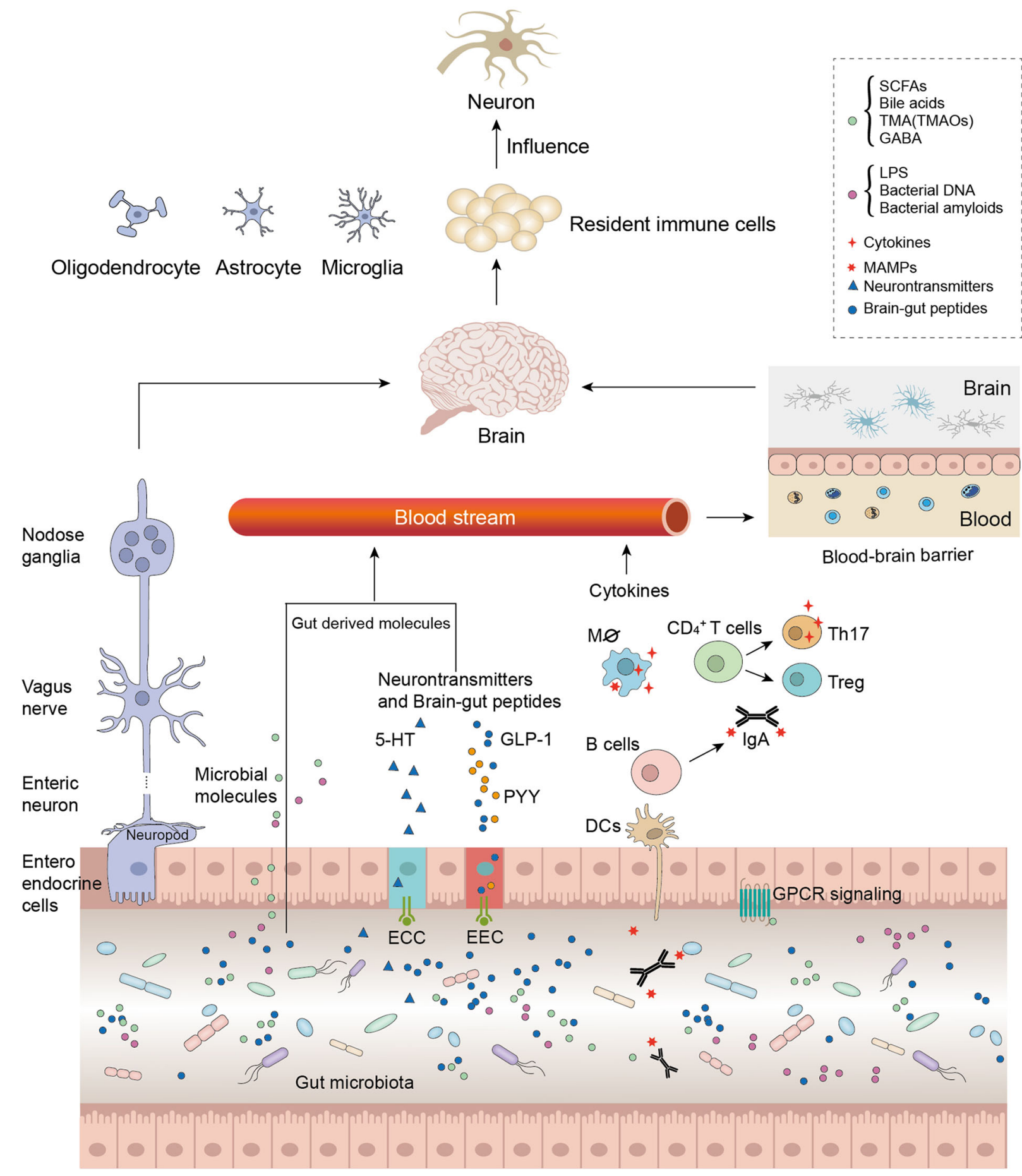

Mucous \& epithelium cells

FIGURE 1 | Microbiota modulates the gut-brain axis through its secretions, including microorganism-associated molecular patterns (MAMPs) and microbial metabolites. As the intestinal permeability decreased due to the microbial molecules, these molecules were involved in generalized gut-brain signaling, such as the immune-modulating pathway, endocrine signaling pathway, the neural signaling pathway, and the neuroendocrine signaling pathway. Neurotransmitter-like substances such as gammaaminobutyric acid (GABA) directly influence the central nervous system (CNS) through nerve pathways; other gut-derived substances such as MAMPs and short-chain fatty acids (SCFAs) influence the CNS by decreasing blood-brain barrier (BBB) permeability. Furthermore, these microbial molecules activate immune resident cells or neuron cells, which accelerate neurodegenerative disease (ND) physiopathology. 
for developing a therapeutic approach for the NDs characterized by protein misfolding such as $\mathrm{AD}(66)$.

\subsubsection{Nervous System Modifications}

The bidirectional communication network comprises the CNS, autonomic nervous system (ANS), enteric nervous system (ENS), and the hypothalamic-pituitary-adrenal (HPA) axis.

Microbiota communicates with the brain via the vagus nerve. The absence of specific neurochemical and behavioral effects in vagotomized germ-free mice demonstrated that the vagal pathway is an important communication route between the gut and the brain (37). The ENS interacts with the CNS through the vagus nerve by generating direct neurochemical signals from the gut microbiota to the brain and vice versa (67). The HPA axis is a part of the limbic system having structures such as the hippocampus, hypothalamus, and amygdala and involving memory and emotional responses. Chronic stress or proinflammatory cytokines such as interleukin (IL)- 6 increase the level of corticotropin-releasing factor secreted from the hypothalamus and adrenocorticotropic hormone (ACTH) secreted from the pituitary gland, which results in the secretion of cortisol from the adrenal gland, which is toxic to the brain (68).

Consequently, the combination of neural and hormonal communications facilitates the CNS to influence the activities and function of intestinal cells $(69,70)$. Moreover, gut microbiota affects host health by modulating gut cells and maintaining intestinal metabolic and immune homeostasis (71-73). For example, microbial intestinal dysbiosis and increased intestinal permeability associated with Clostridium overgrowth are considered a feature of immune-related intestinal and extraintestinal disorders (74).

Interestingly, the microbiota also alters the production of neurotransmitters and hormones such as dopamine, adrenaline, noradrenaline, serotonin (5-HT), gamma-aminobutyric acid (GABA), glucagon-like peptide-1, and peptide YY or their precursors, which act on the CNS or ENS directly via the vagus nerve or indirectly by entering the circulation (Figure 1) $(38,75)$.

\subsubsection{Modification of Immune System}

Gut microbiota plays an indispensable role in the maturation of the host immune system and intestinal homeostasis (4). The dysfunction of the interaction between microbiota and immune system induces immune signaling, thus indicating implications in CNS development and NDs (24). Studies have shown that the gut microbiota is associated with the regulation of some immune signaling pathways such as the inflammasome signaling pathway, type I interferon signaling pathway (IFN-I), and nuclear factor $(\mathrm{NF})-\kappa \mathrm{B}$ signaling pathway $(18,76)$.

Compared with the wild-type mouse model, the ASC-, caspase-1-, and IL-18 (typical inflammasomes) knockout mouse model showed altered $\alpha$-diversity in a study (77). Furthermore, evidence suggests that the activated inflammasome and the increased level of pro-inflammatory cytokines such as IL-1 $\beta$, IL-6, and IL-18 proteins are associated with the major depressive disease (78). In MS, inflammasome signaling can be inhibited by IFN (79). IFN-I is associated with the maturation of dendritic cells (DCs), enhancement of cytotoxic $\mathrm{T}$ cells, and bidirectional interaction between the host and the gut microbiota (80). However, commensal lactic acid bacteria can trigger the Toll-like receptor (TLR) 3-mediated IFNI secretion of intestinal DCs (81). In addition, because the critical transcription factor contributes to immune response, the increased NF- $\kappa \mathrm{B}$ level with the cooperative expression of TNF$\alpha$ was detected both in the intestinal and hippocampal zones, which are associated with amnesia; the symptoms of amnesia and colitis were attenuated after the recovery of gut microbiota $\alpha$-diversity was disturbed in a colitis model (82).

\section{FROM BENCH TO CLINIC: THE EMERGING ROLE OF GUT MICROBIOTA IN NEURODEGENERATIVE DISEASES}

Gut dysbiosis has adverse effects on cognition, behavior, and motor performance (83). The frailty of the gut on the physiology alters the intestinal environment and gut microbiota (Figure 2) (22). The gut microbiota, being considered as potential diagnostic features of NDs, affects different pathophysiological stages in cognitive impairments. In this section, we review the involvement of microbiota in typical NDs (Table 1).

\subsection{Alzheimer's Disease}

$\mathrm{AD}$ is the most common ND in the elderly population, and agerelated adult dementia accounts for $60 \%-70 \%$ of dementia cases; the lifetime AD risk is approximately $20 \%$ in women and $10 \%$ in men (104). AD is chronic and irreversible and involves progressive cognitive impairment and behavioral changes such as memory loss, disorientation, and loss of mobility, which are characterized by synaptic dysfunction by synthesized factors, accumulation of neurotoxic protein aggregates, age-related processes, neuroinflammation, lead neuron, and synaptic loss (105-107). A classical pathology of AD involves amyloid-beta (A $\beta)$ extracellular neurotic plaques, which are distributed throughout the cerebral cortex, and over-phosphorylated Tau protein-containing neurofibrillary tangles, which primitively occur in the medial temporal lobe and then diffuse to the isocortical regions of the temporal, parietal, and frontal lobes (108-110). Studies have reported that the deposition of $A \beta$ and Tau protein occurs 10-20 years before the onset of clinical dementia symptoms (111). Numerous studies on AD treatment or intervention strategies in animal models have achieved promising results. Unfortunately, drugs targeting the pathological procedure have been found not effective in $\mathrm{AD}$ clinical treatment (112).

\subsubsection{Involvement of Microbiome in Alzheimer's Disease}

The frailty of the host is related to the reduced diversity of core microbiota groups such as Lactobacilli, Bacteroides, and Prevotella and the increased abundance of Ruminococcus, Atopobium, and Enterobacteriaceae (113). Interestingly, these 


\section{Normal adult}

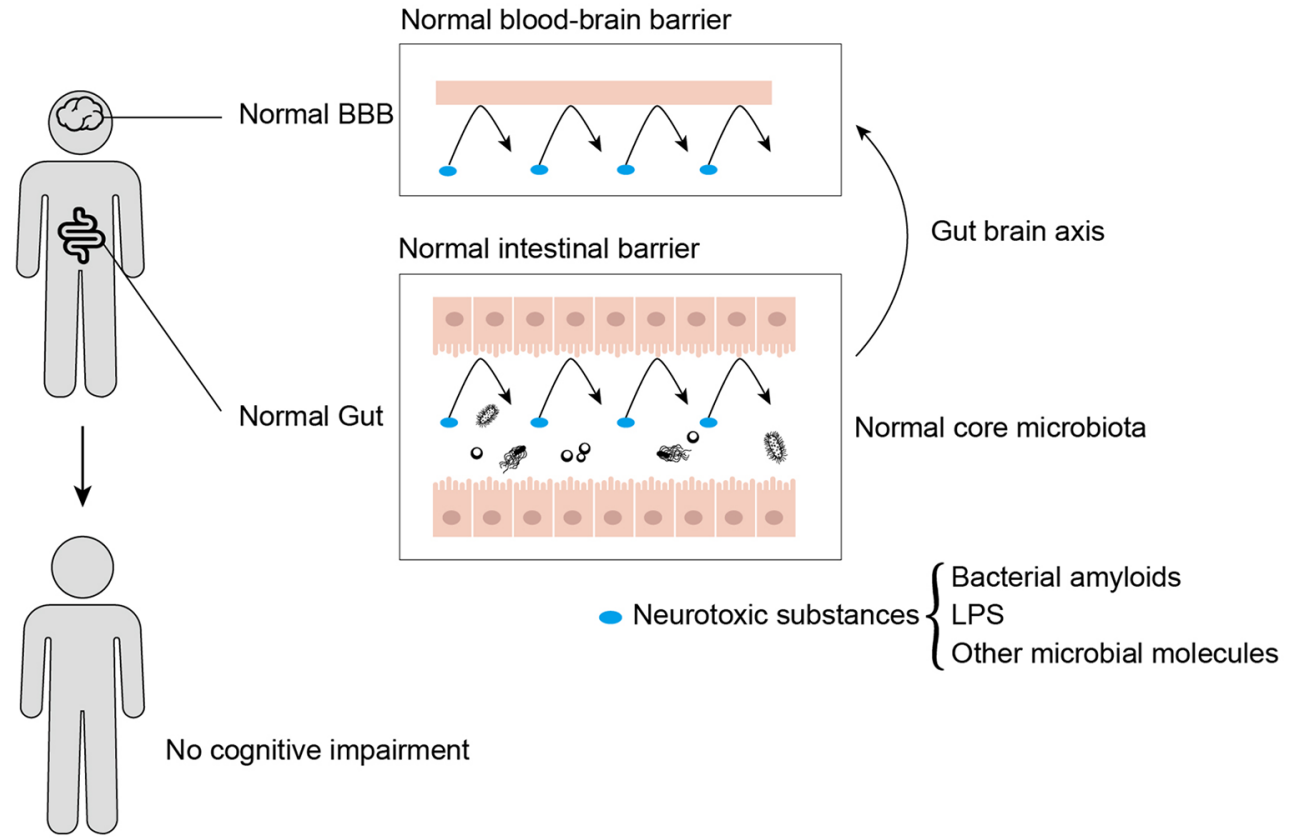

\section{Unhealthy lifestyle / Elderly / Injured Gut}

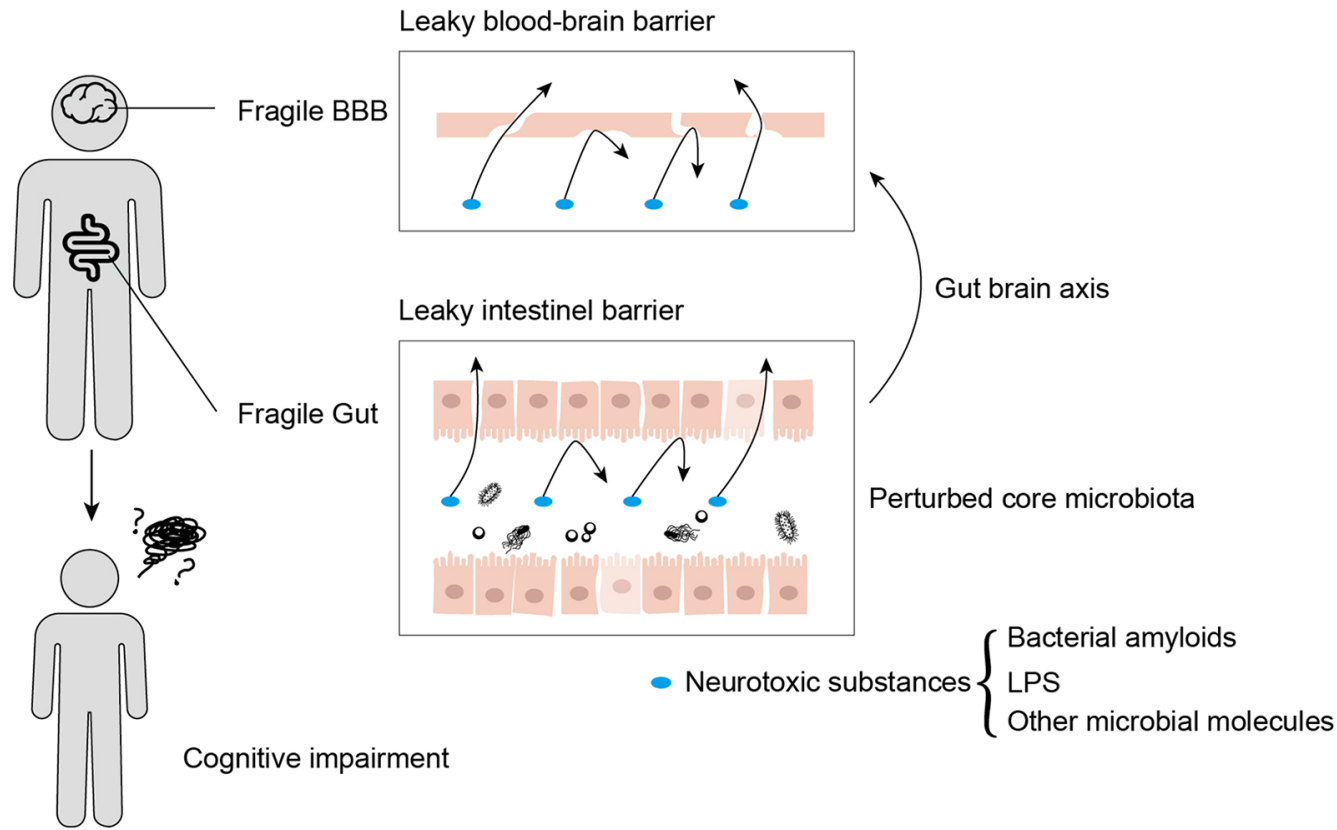

FIGURE 2 | Neurotoxic substances that are produced by gut microbiota influence cognitive impairment progression by transmitting from gut to brain, in which intestinal barrier and blood-brain barrier served as crucial customs passes. Moreover, these neurotoxic substances cannot traverse from usual intestinal and bloodbrain barriers, while aging, unhealthy lifestyles, and acute or chronic enteritis would disrupt the integrity of both intestinal and blood-brain barriers, leading to cognitive impairment. 
TABLE 1 | Involvements of gut microbiota in neurodegenerative disease.

\begin{tabular}{|c|c|c|c|}
\hline Bacterial genus & Possible involvements & $\begin{array}{l}\text { Related neurodegenerative } \\
\text { diseases }\end{array}$ & Reference \\
\hline $\begin{array}{l}\text { Escherichia, Pseudomonas, Staphylococcus, Streptococcus, } \\
\text { Bacillus, Mycobacteria, Citrobacter, Klebsiella, Salmonella }\end{array}$ & $\begin{array}{l}\text { Bacterial amyloid, FapCs, Translocate } \\
\text { across BBB through GBA }\end{array}$ & Alzheimer's disease & Cao et al. (84) \\
\hline Lactobacillus & $\begin{array}{l}\text { GABA, Balance the regulation of cortical } \\
\text { excitability and neural excitation-inhibition }\end{array}$ & Alzheimer's disease & $\begin{array}{l}\text { Ciminelli et al. (85) } \\
\text { Auger et al. (86) }\end{array}$ \\
\hline Bifidobacterium & $\begin{array}{l}\text { GABA, Balance the regulation of cortical } \\
\text { excitability and neural excitation-inhibition }\end{array}$ & Alzheimer's disease & Auger et al. (86) \\
\hline $\begin{array}{l}\text { Proteobacteria, } \\
\text { Bacteroidetes, } \\
\text { Firmicutes, } \\
\text { Actinobacteria, } \\
\text { Lachnospiracea }\end{array}$ & Unknown & Alzheimer's disease & $\begin{array}{l}\text { Vogt et al. (87) } \\
\text { Zhuang et al. (88) } \\
\text { Ling et al. (89) }\end{array}$ \\
\hline $\begin{array}{l}\text { Roseburia, } \\
\text { Faecalibacterium }\end{array}$ & Can produce SCFAs & Parkinson's disease & Nuzum et al. (90) \\
\hline Pseudomonas & Fap, change of $\alpha$-synuclein & Parkinson's disease & Christensen et al. (91) \\
\hline Enterobacteriaceae & Curli, $\alpha$-synuclein aggregation & Parkinson's disease & Sampson et al. (92) \\
\hline $\begin{array}{l}\text { Clostridium coccoides, Bacteroides fragilis, } \\
\text { Prevotellaceae }\end{array}$ & Unknown & Parkinson's disease & $\begin{array}{l}\text { Hopfner et al. (93) } \\
\text { Hasegawa et al. (94) } \\
\text { Scheperjans et al. (95) }\end{array}$ \\
\hline Hydrogen-product bacteria & Reduced dopaminergic loss & Parkinson's disease & $\begin{array}{l}\text { Fujita et al. (96) } \\
\text { Yorikata et al. (97) } \\
\text { Guo et al. (98) }\end{array}$ \\
\hline $\begin{array}{l}\text { Coriobacteriales, Erysipelotrichales, Bacteroidales, } \\
\text { Burkholderiale }\end{array}$ & Unknown & Huntingdon disease & $\begin{array}{l}\text { Kong et al. (99) } \\
\text { Radulescu et al. (100) }\end{array}$ \\
\hline Clostridium & Decrease level of SCFA secretion & Multiple sclerosis & Miyake et al. (101) \\
\hline $\begin{array}{l}\text { Firmicutes, Bacteroidetes, } \\
\text { Prevotella }\end{array}$ & Unknown & Multiple sclerosis & $\begin{array}{l}\text { Cosorich et al. (102) } \\
\text { Chen et al. (103) }\end{array}$ \\
\hline
\end{tabular}

BBB, blood-brain barrier; GBA, gut-brain axis; GABA, gamma-aminobutyric acid; SCFA, short-chain fatty acid.

microbial communities are associated with the host's mood and behavior, which are precipitating factors for cognitive impairment. Studies have reported that gut microbiota is altered in $\mathrm{AD}$. When $\mathrm{AD}$ patients were compared with healthy controls, $\mathrm{AD}$ patients exhibited diverse microbiota, an increased abundance of Bacteroidetes, and a reduced abundance of Firmicutes, Proteobacteria, and Actinobacteria (88, 89). Moreover, the composition of the gut microbiota of SAPM8 mice, which exhibited learning and cognitive impairment similar to $\mathrm{AD}$ patients, revealed conspicuous character divergence compared with that of the healthy control; the correlation density and clustering operational taxonomic unit of gut microbiota decreased (87). The increasing abundance of microbiota such as norank $f$ Lachnospiracea, unclassified $f$ Lachnospiraceae, and Alistypes in SAPM8 models is consistent with that reported in $\mathrm{AD}$ patients in another study (114). The analogous shifts of the microbiota were also found in other transgenic AD pathology-like mouse models compared with 3year-old wild-type mouse models; the microbiota composition was similar but the diversity started changing after 6 months of age, and the AD pathology-like models showed increased abundance of Proteobacteria and Erisilopelotrichaeae (115). In addition, neuroinflammation and amyloidosis are affected by the perturbation of gut microbiota diversity induced by antibiotics in the $\mathrm{AD}$ mouse model $(116,117)$.

Fecal microbiota transplantation (FMT) is considered both a typically investigative and a potential therapeutic approach for ND (Figure 3). A study reported increased cerebral A $\beta$ pathology in a germ-free amyloid precursor protein (APP) transgenic mouse model with FMT compared with that in a cognitively impaired mouse model, whereas wild-type mice with FMT exhibited less effective pathology (118). Compared with germ-free mice with FMT from AD patients and healthy donors, the FMT model showed cognitive impairment (119). Correspondingly, frequent FMT from healthy wild-type mouse models to $\mathrm{AD}$ pathology-like transgenic mice effectively reactivated the glial cells and reduced $A \beta$ pathology, neurofibrillary tangles, and cognitive impairment (120).

\subsubsection{Modifications of Microbial Molecules in Alzheimer's Disease}

As previously mentioned, the gut microbiota-derived molecules may cause gut dysbiosis, and GBA is a crucial precipitating factor for AD. LPS, peptidoglycan (PGN), bacterial epigenetics, bacterial DNA, and bacterial amyloids are the typical MAMPs associated with AD. The cluster differentiation 14 (CD14) receptor, termed LPS receptor, coordinates with the microglia to promote $A_{\beta}$ deposition, stimulates TLR4 in astrocytes that is a ligand for $A_{\beta}$ metabolism, and accelerates neuron loss $(58,121,122)$. AD patients showed 2-fold higher levels of LPS in the neocortex and 3-fold higher LPS levels in the hippocampus than healthy controls (123). Andreadou et al. (124) reported an increased level of LPS in both cerebrospinal fluid and serum in $\mathrm{AD}$ patients and a negative correlation between the LPS level and cognitive state. In AD mouse models, LPS induced cognitive impairment, neuroinflammation, and sickness behaviors such as anxiety and fear $(125,126)$. PGN is a dominant component of the Gramnegative cell wall that is recognized by specific pattern-recognition 

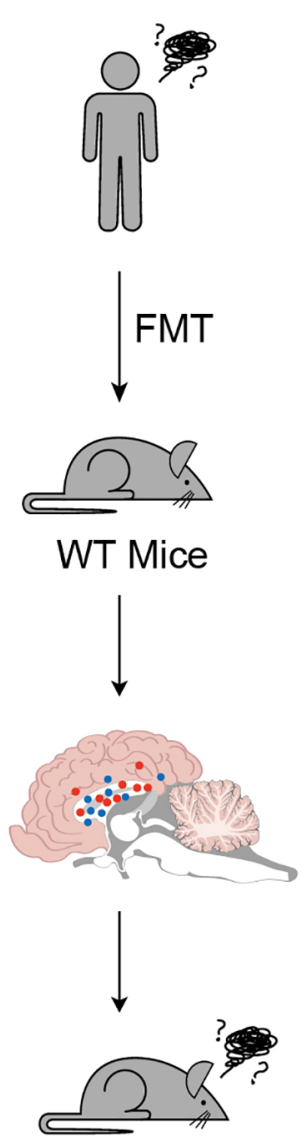

Cognitive impairment

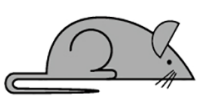

Cognitive impairment
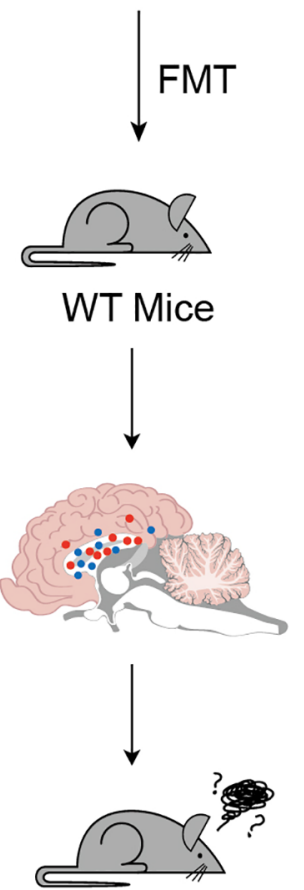

Cognitive impairment

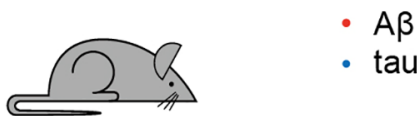

WT Mice
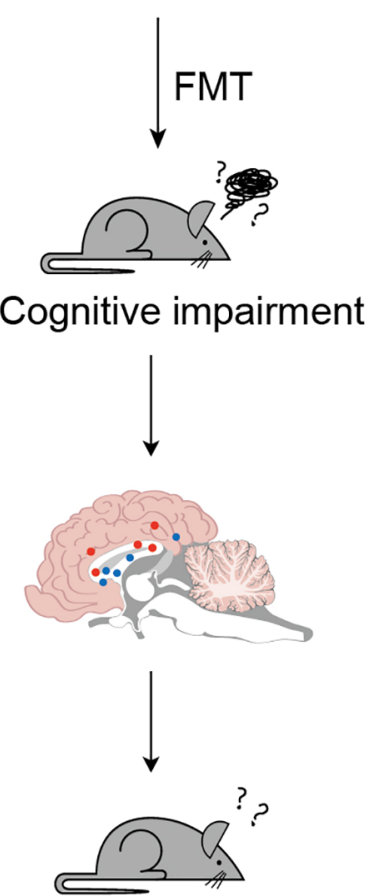

Ameliorated Cognitive impairment

FIGURE 3 | Served as both a typically investigative and a potential therapeutic approach for cognitive impairment, utilize fecal microbiota transplantation (FMT) has been spread. These three typical trials suggested potential prevention or clinical therapies for cognitive impairment.

receptors (PRRs) of the innate immune system (127). Gut microbiota-derived PGN could traverse the BBB and affect gene transcription and social behaviors (128). Currently, the pathogenic role of bacterial DNA in $\mathrm{AD}$ is being considered. In in vitro $\mathrm{AD}$ pathological assays, Tetz et al. $(129,130)$ reported the induction of Tau aggregation, as well as $A \beta$ misfolding and aggregation by bacterial eDNA. Bacterial amyloids are the extracellular proteins secreted by Escherichia, Pseudomonas, Staphylococcus, Streptococcus, Bacillus, Mycobacteria, Citrobacter, Klebsiella, and Salmonella species and could translocate across the BBB through GBA associated with NDs (84). In in vitro assays, specific bacterial amyloid FapCs were found to be $A \beta$-binding hot spots that participate in the incorporation of $\mathrm{A} \beta$ nanofibrils (74). In zebrafish $\mathrm{AD}$ models, fragment amyloids from infectious bacteria enhanced $A \beta$ pathogenesis and further made the cognitive impairment more severe (131). The crucial role of SCFA in $\mathrm{AD}$ has emerged. In an in vitro trial, SCFA inhibited $A_{\beta}$ aggregation (132). By comparing the $\mathrm{AD}$ mouse model and wild-type mouse model of different ages, the perturbed $\alpha$-diversity of microbiota and decreased level of SCFAs were found to be associated with the bacterial amyloid deposition and ultrastructural alteration in the gut (133). In a similar trial by Zheng et al. (134) on the content of SCFAs in fecal samples, the $\mathrm{AD}$ mouse model showed a significant difference in the levels of propionic acid, isobutyric acid, 3-hydroxy butyric acid, and 3hydroxisopropyl acid as well as the decreased levels of lactic acid, 2-hydroxy butyric acid, 2-hydroxy isobutyric acid, levulinic acid, and valproic acid compared with wild-type mice. In addition, an in vitro study suggested that sodium butyrate could protect the neuron cells from A $\beta$-induced neurotoxic effects (135).

In co-metabolism by host and gut microbiota, bile acids maintain the secondary function of steroid hormones by serving as signaling molecules that affect the cellular receptors associated with CNS development (136), including membranebound receptors (such as sphingosine-1-phosphate receptor 2 and Takeda G-protein-coupled bile acid receptor 5) and nuclear receptors (such as Farnesoid X receptor) (137) In a study of 1,562 clinical cases, diverse bile acid metabolites in serum were quantified, which revealed that bile acids are the biomarker of AD pathology (138).

TMAOs are the metabolites of dietary choline. In the network-based algorithm engineered by $\mathrm{Xu}$ and Wang (139), 
TMAO ranked first in 56 human $\mathrm{AD}$ biomarkers. The increase in TMAO is detectable in patients with cognitive impairment (65). In an in vitro trial, researchers observed that TMAO participates in $\mathrm{A} \beta$ aggregation (140). In $\mathrm{AD}$ mouse models, TMAO administration accelerated the senescence of hippocampal cells and $A \beta$ pathology and aggravated cognitive impairment (141). In another study, long-term cognitive impairment was ameliorated with reduction in the TMAO proportion in the plasma of the AD mouse model (142). This finding suggested that TMAO exacerbates ND pathology and cognitive impairment; however, the changes in serum TMAO in ND patients remain to be investigated.

GABA, the precursors of which are glutamates metabolized by the genera Lactobacillus and Bifidobacterium, is an essential inhibitory neurotransmitter, which balances the regulation of cortical excitability and neural excitation-inhibition. GABA plays a crucial role in CNS development (85). A study reported that the inhibitory GABA signaling could ameliorate cognitive impairment in the cognitive impairment mouse model (86). The disruption of GABA balance is considered a contributor to cognitive impairment, warranting further studies.

\subsection{Parkinson's Disease}

$\mathrm{PD}$ is a progressive ND, with aging as the main risk factor, and its estimated morbidity is $6 \%(143,144)$. PD can be manifested by both motor and non-motor symptoms. Motor symptoms include resting tremor, bradykinesia, postural instability, and rigidity. For some PD patients, parkinsonian tremor is the only visible symptom during diagnosis (145). Non-motor symptoms include cognitive decline, depression, anxiety, dysautonomia, dementia, and sleep disturbances (145). PD is closely related to gastrointestinal complications such as bloating, nausea, and abdominal discomfort (146).

One of the general pathologies of PD is the loss of dopaminergic neurons in the substantia nigra pars compacta (SNpc) located in the midbrain, which is mainly responsible for motor disorders. The degeneration of dopaminergic neurons is closely associated with Lewy bodies, which are cytoplasmic inclusions that comprise insoluble alpha-synuclein ( $\alpha$-Syn) aggregates (147). The six stages of such Lewy pathology in PD have been demonstrated. The disease was proposed to start in the gut with misfolded $\alpha$-Syn and then be localized to the brain (148).

\subsubsection{Involvement of Microbiome in Parkinson's Disease}

Despite intensive studies on PD, no effective treatments with sustained benefits are available. Recent findings have shown that gut microbiota is closely related to PD and causes changes in microbe diversity and metabolites. In several case-control studies, an increasing abundance of Lactobacillaceae, Barnesiellaceae, and Enterococcacea was observed and a decreasing abundance of Clostridium coccoides, Bacteroides fragilis, and Prevotellaceae have been observed in PD patients compared with those in healthy controls (93-95). PD patients may also have increased intestinal permeability and bacterial overgrowth in the small intestine $(149,150)$. A recent study in the $\alpha$-Syn-overexpressing (ASO) mice showed that the gut microbiota plays a crucial role in PD manifestation. ASO mice administered feces from PD patients showed increasing motor symptoms compared with the mice administered healthy feces (151). A case report of a PD patient with healthy FMT showed the temporary improvement of leg tremors and other PD symptoms (152).

\subsubsection{Modifications of Microbial Molecules in Parkinson's Disease}

Gut-derived microbial molecules are considered crucial biomarkers of PD, in addition to $\mathrm{AD}$. LPS acts as a PDinducing factor that causes intraneural LPS to activate microglia and dopaminergic neuron degeneration. In a mouse model, microglial nicotinamide adenine dinucleotide phosphate oxidase expression was shown to be regulated by LPS, leading to mitochondrial dysfunction, which further initiated neurotoxic effects $(153,154)$. Currently, LPS administration is extensively used to induce PD-like pathology in mouse models (155). PGNs are recognized as exogenous foreign substances by the host immune system, and they are known as ligands with PRRs because they are unique to bacteria (127). A recent study on the PGN recognition protein genes suggested its causative role in gut microbiota and gut homeostasis related to PD risk $(156,157)$.

Moreover, two types of bacterial amyloids, namely, Fap and Curli, are associated with PD pathology. Fap produced by Pseudomonas induced a conformational change in $\alpha$-Syn in an in vitro trial (91). Curli produced by Enterobacteriaceae promoted $\alpha$-Syn aggregation and motor impairment in a mouse model (92).

After comparing fecal samples of patients with those of healthy controls, patients with PD showed SCFA reduction and altered microbiota composition (57). Interestingly, the plasma SCFA levels increased with the severity of PD and antiparkinsonian medical approaches (158). In addition, the colonization of SCFA-producing bacteria such as Roseburia and Faecalibacterium was found to be more in healthy controls than that in patients with PD (90).

Whether TMAO can be used as a diagnostic biomarker of PD is unknown. However, it was detectable in the CSF of a PD mouse model (141). TMAO level alterations in PD are still controversial because its high plasma levels were associated with terminal $\mathrm{PD}$, whereas low plasma TMAO levels were associated with increased risk of early-stage PD $(159,160)$.

Molecular hydrogen is a common by-product of carbohydrate fermentation in the host microbiota. Due to the bidirectional translocation from the cell membrane and antioxidant properties, molecular hydrogen might have neuroprotective effects and is being used in bacterial overgrowth in the small intestine (161). A clinical study revealed the low abundance of bacterial hydrogen products in patients with $\mathrm{PD}$ compared with that in healthy controls (162). Inflammation and peripheral blood cell apoptosis in healthy adults can be reduced by drinking hydrogen-rich water (163). Moreover, in a previous study using a PD mouse model, dopaminergic loss was shown to reduce with drinking of hydrogen water (96). Moreover, regular drinking of hydrogen water reduced motor impairment in 
patients with PD (97). A similar study using an autism spectrum disorder mouse model also reported amelioration of the autisticlike behavior in mice (98). However, the specific mechanism of hydrogen in modulating cognitive impairment is still unknown.

\subsection{Huntington Disease}

$\mathrm{HD}$ is an autosomal dominant rare ND with an estimated global prevalence of 2.7 cases in 100,000 people, with the onset age between 35 and 44 years $(164,165)$. The main manifestations of HD include cognitive impairment, psychiatric disorder, and motor symptoms. Motor disturbance progresses into dysphagia with weight loss and aspiration difficulties, leading to fatality $(164,166)$. In addition, the abnormal expansion of HTT results in HTT dysfunction in brain development, transcriptional process, histone modification, and mitochondrial function, which eventually triggers the aforementioned manifestations $(165,167)$. Despite the availability of explicit information on HD symptoms and pathogenesis, no effective treatment is available for curing the disease or delaying its progression.

\subsubsection{Involvement of Microbiome in Huntington Disease}

Emerging evidence has linked gut microbiota with neurological health, thus creating the possibility of bringing gut microbiota into HD diagnosis and treatment (168). HD may be characterized by changes in the abundance or diversity of gut microbiota, and such changes may include sexual differences (169). A recent study compared the gut microbiota in an HD mouse model with that in wild-type mice and reported an increase in the abundance of Bacteroidales and Lactobacillales and a decrease in the abundance of Clostridiales in a male HD mouse model. By contrast, an increase in the abundance of Coriobacteriales, Erysipelotrichales, Bacteroidales, and Burkholderiale and a decrease in the abundance of Clostridiales were observed in female HD mice. Furthermore, male HD mice showed higher microbial diversity than both female and wildtype mice (99). Another study showed the decreased levels of myelin-related proteins and mature oligodendrocytes in the prefrontal cortex in microbiota-deficient mice, which led to reduced callosal myelination and white matter plasticity (100); the study revealed the effect of the lack of microbiota in aggravating internal HD phenotypes.

\subsubsection{Modifications of Microbial Molecules in Huntington Disease}

In addition to the relation between $\mathrm{HD}$ and gut microbiota diversity, some SCFAs and bioactive metabolites derived from gut microbiota secretion are evident in $\mathrm{HD}$ onset and progression, which mainly act on the biological processes of the GBA (170). Serotonin, tyrosine, 2-hydroxyphenylacetic acid, 3-hydroxyphenylacetic acid, and 4-hydroxyphenylacetic acid can cause diet and bioactive compound dysbiosis in the GBA, whereas indole-3-propionic acid can lead to intestinal permeability (171). More studies on such gut microbiotaderived metabolites can help in understanding the complex relationship between gut microbiota and HD and shed light on the early diagnosis and treatment of HD.

\subsection{Multiple Sclerosis}

MS is a chronic inflammatory and demyelinating disorder in the CNS. MS exhibits different phenotypes, with approximately $15 \%$ cases in a primary progressive MS (PPMS) course and 85\% cases in a relapsing-remitting MS (RRMS) course (172). PPMS is a progressive neurologic disorder characterized by spastic paraparesis and sphincter dysfunction (173). A patient presenting with clinically isolated syndromes can be suspected as having RRMS, which is characterized by sustained neurologic symptom relapse and recovery $(174,175)$. The essential pathology of MS remains to be elucidated. However, MS development may be affected by both internal and external factors, eventually leading to immune dysregulation.

\subsubsection{Microbiota Implicates Internal Factor Effect on Multiple Sclerosis}

Recent studies have shown that internal gut microbiota significantly effects MS and can be affected by environmental factors (176). The 16S rRNA sequencing of intestinal microbiota showed a high abundance of the phylum Firmicutes and lower abundance of the phylum Bacteroidetes in patients with MS than those in healthy controls (102). The increased abundance of Euryachaeota and Akkermansia has been observed in untreated patients with MS compared with that in healthy controls (177). Other studies have pointed out specifically that the decreased abundance of Prevotella in patients with RRMS can increase the disease activity (103). The reduction in Clostridium abundance in patients with RRMS, leading to a decreased level of SCFA secretion, was also observed in a study (101). Considering the extent of such changes in patients with MS, FMT trials have further proven the relationship between gut microbiota and MS. The transplant of MS microbiota in mouse models resulted in an increased experimental autoimmune encephalomyelitis incidence, resulting in more severe MS symptoms $(178,179)$. Currently, two human FMT trials have reported the successful amelioration of MS symptoms $(180,181)$.

\subsubsection{Microbiota Implicates External Factor Effects on Multiple Sclerosis}

External environmental factors such as Epstein-Barr virus infection, smoking, and vitamin D intake also have significant effects on MS progression. The relationship between vitamin D and MS has led to research on an upsurge in the effect of diet in MS treatment (182). Diets can affect the diversity and levels of gut microbiota and then indirectly affect MS development (183). Patients with obesity showed the same phenomenon of increase in Firmicutes and Actinobacteria abundance similar to those in patients with MS. Additionally, obese patients with MS had a reduced abundance of Bacteroidetes compared with patients having normal weight (184). Moreover, obese patients exhibit low levels of 25-hydroxyvitamin D3 (vitamin D storage form) and consequently high risks of MS development (185). Dietary studies in patients with MS have shown the positive effects of dietary intervention with vitamin $\mathrm{D}$ supplement in low-calorie diets, alleviating the chronic inflammatory symptoms of MS (186). Recently, intermittent fasting has been introduced into MS 
treatment because of its significant effects, including the supply the abundant of gut microbiota and the secretion of leptin and glutathione (187). All these studies have shown that diet can be considered as an MS treatment alternative.

\section{CONTROVERSIES AND PERSPECTIVES}

NDs are systemic diseases that can be studied in diverse disciplines including microbiology and neuroscience. Several pieces of evidence in preclinical, clinical, in vitro, and in vivo studies have suggested the relationship of gut microbiota with brain shapes, neurological processes, and cognitive behavior (Figure 2). However, the findings of most studies are less reliable because of limited sample sizes. The effect of microbiota on ND pathophysiology in FMT trials is unclear because of the unreliable microbiota, and most trials have focused on animal models.

Comprehensive, normalized, and rigorous analysis and evaluation standards are needed because of differences in cohorts, lifestyles, ages, and genders across studies. The differences across studies can be summarized as follows.

First, tremendous regional differences have been observed, for example, the abundance of gut Bacteroides was reported to be high in $\mathrm{AD}$ patients from the USA, whereas it was reported to be low in $\mathrm{AD}$ patients from China $(87,188)$. Two studies from different provinces in China also showed an inverse change in Blautia abundance $(188,189)$. Second, a few studies have reviewed the effects of specific species of microbiota on ND pathology; however, the mechanisms remain unclear. For example, the abundance of Akkermansia increased in human patients with $\mathrm{AD}, \mathrm{PD}$, and MS, whereas Akkermansia intragastric administration in an AD mouse model produced protective effects on cognitive impairments; increased Akkermansia proportion in $\mathrm{AD}$ and $\mathrm{PD}$ mouse models has also been reported to ameliorate the underlying pathology (87, 177, 190-192). Based on the aforementioned findings, we speculate that controversial experimental results were obtained because of the limited pathogenesis of ND mouse models. Human ND etiologies are quite intricate, involving longterm manifold metabolic disorders, gut microbiota alteration, gene mutation, and various hereditary factors, whereas most mouse model etiologies rely on gene editing or medical injection, which might lead to inconsistent pathogenic processes (24, 193-201). Third, studies have demonstrated that microbiota altered with aging; yet, no evidence is available to confirm whether the altered microflora is healthy, unhealthy, stable, or vulnerable $(10,15,22$, $113,202)$. Construction of a standard ND patient fecal microbiota bank can revolutionize the analysis of fecal microbiota through a

\section{REFERENCES}

1. Cottler LB, Zunt J, Weiss B, Kamal AK, Vaddiparti K. Building Global Capacity for Brain and Nervous System Disorders Research. Nature (2015) 527(7578):S207-S13. doi: 10.1038/nature16037

2. Ravindranath V, Dang H-M, Goya RG, Mansour H, Nimgaonkar VL, Russell VA, et al. Regional Research Priorities in Brain and Nervous System Disorders. Nature (2015) 527(7578):S198-206. doi: 10.1038/nature16036 noninvasive ND diagnostic approach. Furthermore, more precise animal models that simulate both human ND pathology and its intestinal environments are needed.

Similarly, the nervous system and BBB become weaker with aging $(49,203,204)$. Thus, it is essential to understand how the vulnerability of neurons and BBB affects GBA modulation. Further studies are required to assess the long-term effect of GBA stability as a new "endocrine organ" on ND pathology (48). Specific microbial molecule modulation in gut-brain signaling both chemically and physically may provide a therapeutic approach targeted on microbiome effects. For example, the application of microbiota-targeted psychotropic medicines without dependency, which could reduce the dependency caused by existing psychotropic drugs or the drugs that inhibit the proliferation of specific ND-causing microbiota or bacterial metabolite production, might be a revolutionary therapy.

\section{CONCLUSION}

Gut microbiota influences brain disorders through modulating the immune system, direct neural signaling, and activating the humoral pathway by microbial molecules and some unknown potential pathways. Considerable attention has been paid toward elucidating the unknown mechanism and influence factors; therefore, direct intervention of ND pathophysiology by gut microbiota should be reconsidered. Further studies from bench to clinical on these mysteries are required to better understand the underlying mechanism.

\section{AUTHOR CONTRIBUTIONS}

$\mathrm{HZ}$ and YC wrote the first draft of the article and contributed equally to this work. WW, ZW, GX, ML, and BY contributed substantially to the writing and revised the article. HC designed the figures. WW and PC designed the editorial aim. All authors have made substantial intellectual contributions, are responsible for the paper, and ultimately endorse the submitted version. WW has the primary responsibility for final content.

\section{FUNDING}

This work was supported by the National Natural Science Foundation of China (31872442) and Key Realm R\&D Program of Guangdong Province (2020B0202080002).

3. Arumugam M, Raes J, Pelletier E, Le Paslier D, Yamada T. Enterotypes of the Human Gut Microbiome. Nature (2011) 474(7353):666. doi: 10.1038/ nature 10187

4. Sommer F, Bäckhed F. The Gut Microbiota-Masters of Host Development and Physiology. Nat Rev Microbiol (2013) 11(4):227-38. doi: 10.1038/nrmicro2974

5. Geva-Zatorsky N, Sefik E, Kua L, Pasman L, Tan TG, Ortiz-Lopez A, et al. Mining the Human Gut Microbiota for Immunomodulatory Organisms. Cell (2017) 168(5):928-43.e11. doi: 10.1016/j.cell.2017.01.022 
6. Sonnenburg JL, Sonnenburg ED. Vulnerability of the Industrialized Microbiota. Science (2019) 366(6464). doi: 10.1126/science.aaw9255

7. Macpherson AJ, de Agüero MG, Ganal-Vonarburg SC. How Nutrition and the Maternal Microbiota Shape the Neonatal Immune System. Nat Rev Immunol (2017) 17(8):508-17. doi: 10.1038/nri.2017.58

8. Li Q, Barres BA. Microglia and Macrophages in Brain Homeostasis and Disease. Nat Rev Immunol (2018) 18(4):225-42. doi: 10.1038/nri.2017.125

9. Diaz Heijtz R, Wang S, Anuar F, Qian Y, Björkholm B, Samuelsson A, et al. Normal Gut Microbiota Modulates Brain Development and Behavior. Proc Natl Acad Sci USA (2011) 108(7):3047-52. doi: 10.1073/pnas.1010529108

10. Dinan TG, Cryan JF. Gut Instincts: Microbiota as a Key Regulator of Brain Development, Ageing and Neurodegeneration: Microbiota-Gut-Brain Axis Across the Lifespan. J Physiol (2017) 595(2):489-503. doi: 10.1113/JP273106

11. Erny D, Hrabě de Angelis AL, Jaitin D, Wieghofer P, Staszewski O, David E, et al. Host Microbiota Constantly Control Maturation and Function of Microglia in the CNS. Nat Neurosci (2015) 18(7):965-77. doi: 10.1038/nn.4030

12. Sherwin E, Bordenstein SR, Quinn JL, Dinan TG, Cryan JF. Microbiota and the Social Brain. Science (2019) 366(6465). doi: 10.1126/science.aar2016

13. Needham BD, Kaddurah-Daouk R, Mazmanian SK. Gut Microbial Molecules in Behavioural and Neurodegenerative Conditions. Nat Rev Neurosci (2020) 21(12):717-31. doi: 10.1038/s41583-020-00381-0

14. Lozupone CA, Stombaugh JI, Gordon JI, Jansson JK, Knight R. Diversity, Stability and Resilience of the Human Gut Microbiota. Nature (2012) 489 (7415):220-30. doi: 10.1038/nature11550

15. Yatsunenko T, Rey FE, Manary MJ, Trehan I, Dominguez-Bello MG, Contreras M, et al. Human Gut Microbiome Viewed Across Age and Geography. nature (2012) 486(7402):222-7. doi: 10.1038/nature1 1053

16. Eckburg PB, Bik EM, Bernstein CN, Purdom E, Dethlefsen L, Sargent M, et al. Diversity of the Human Intestinal Microbial Flora. Science (2005) 308 (5728):1635-8. doi: 10.1126/science.1110591

17. Gill SR, Pop M, DeBoy RT, Eckburg PB, Turnbaugh PJ, Samuel BS, et al. Metagenomic Analysis of the Human Distal Gut Microbiome. Science (2006) 312(5778):1355-9. doi: 10.1126/science.1124234

18. Ma Q, Xing C, Long W, Wang HY, Liu Q, Wang R-F. Impact of Microbiota on Central Nervous System and Neurological Diseases: The Gut-Brain Axis. J Neuroinflamm (2019) 16(1):53-14. doi: 10.1186/s12974-019-1434-3

19. Kau AL, Ahern PP, Griffin NW, Goodman AL, Gordon JI. Human Nutrition, the Gut Microbiome and the Immune System. Nature (2011) 474(7351):327-36. doi: 10.1038/nature10213

20. Gonzalez A, Stombaugh J, Lozupone C, Turnbaugh PJ, Gordon JI, Knight R. The Mind-Body-Microbial Continuum. Dialogues Clin Neurosci (2011) 13 (1):55. doi: 10.31887/DCNS.2011.13.1/agonzalez

21. Zhou Y, Hu G, Wang MC. Host and Microbiota Metabolic Signals in Aging and Longevity. Nat Chem Biol (2021) 17(10):1027-36. doi: 10.1038/s41589021-00837-z

22. O'Toole PW, Jeffery IB. Gut Microbiota and Aging. Science (2015) 350 (6265):1214-5. doi: 10.1126/science.aac8469

23. Perry VH, Nicoll JA, Holmes C. Microglia in Neurodegenerative Disease. Nat Rev Neurol (2010) 6(4):193-201. doi: 10.1038/nrneurol.2010.17

24. Fung TC, Olson CA, Hsiao EY. Interactions Between the Microbiota, Immune and Nervous Systems in Health and Disease. Nat Neurosci (2017) 20(2):145-55. doi: 10.1038/nn.4476

25. Parekh PJ, Oldfield EC, Johnson DA. The Effects of Sleep on the Commensal Microbiota: Eyes Wide Open? J Clin Gastroenterol (2017) 52(3):204-9. doi: 10.1097/MCG.0000000000000965

26. Cai H, Wang C, Qian Y, Zhang S, Zhang C, Zhao W, et al. Large-Scale Functional Network Connectivity Mediate the Associations of Gut Microbiota With Sleep Quality and Executive Functions. Hum Brain Mapp (2021) 42(10):3088-101. doi: 10.1002/hbm.25419

27. Matenchuk BA, Mandhane PJ, Kozyrskyj AL. Sleep, Circadian Rhythm, and Gut Microbiota. Sleep Med Rev (2020) 53:101340-. doi: 10.1016/ j.smrv.2020.101340

28. Surana NK, Kasper DL. Moving Beyond Microbiome-Wide Associations to Causal Microbe Identification. Nature (2017) 552(7684):244-7. doi: 10.1038/ nature25019

29. Bucci V, Bradde S, Biroli G, Xavier JB. Social Interaction, Noise and Antibiotic-Mediated Switches in the Intestinal Microbiota. PloS Comput Biol (2012) 8(4):e1002497. doi: 10.1371/journal.pcbi.1002497
30. O'Toole PW, Shiels PG. The Role of the Microbiota in Sedentary Lifestyle Disorders and Ageing: Lessons From the Animal Kingdom. J Intern Med (2020) 287(3):271-82. doi: 10.1111/joim.13021

31. Irwin MR, Opp MR. Sleep Health: Reciprocal Regulation of Sleep and Innate Immunity. Neuropsychopharmacology (2017) 42(1):129-55. doi: 10.1038/ npp. 2016.148

32. Rothhammer V, Borucki DM, Tjon EC, Takenaka MC, Chao C-C, ArduraFabregat A, et al. Microglial Control of Astrocytes in Response to Microbial Metabolites. Nature (2018) 557(7707):724-8. doi: 10.1038/s41586-0180119-x

33. Mossad O, Erny D. The Microbiota-Microglia Axis in Central Nervous System Disorders. Brain Pathol (2020) 30(6):1159-77. doi: 10.1111/ bpa. 12908

34. Mosher KI, Wyss-Coray T. Go With Your Gut: Microbiota Meet Microglia Nat Neurosci (2015) 18(7):930-1. doi: 10.1038/nn.4051

35. Pascoal TA, Benedet AL, Ashton NJ, Kang MS, Therriault J, Chamoun M, et al. Microglial Activation and Tau Propagate Jointly Across Braak Stages. Nat Med (2021) 27(9):1592-9. doi: 10.1038/s41591-021-01456-w

36. Portal-Celhay C, Bradley ER, Blaser MJ. Control of Intestinal Bacterial Proliferation in Regulation of Lifespan in Caenorhabditis Elegans. BMC Microbiol (2012) 12(1):49-. doi: 10.1186/1471-2180-12-49

37. Forsythe P, Bienenstock J, Kunze WA. Vagal Pathways for MicrobiomeBrain-Gut Axis Communication. Adv Exp Med Biol (2014) 817:115-33. doi: 10.1007/978-1-4939-0897-4_5

38. Strandwitz P. Neurotransmitter Modulation by the Gut Microbiota. Brain Res (2018) 1693(Pt B):128-33. doi: 10.1016/j.brainres.2018.03.015

39. Hyland N, Stanton C. The Gut-Brain Axis : Dietary, Probiotic, and Prebiotic Interventions on the Microbiota. London, UK: Academic Press is an imprint of Elsevier (2016).

40. Dinan TG, Cryan JF. Gut-Brain Axis in 2016: Brain-Gut-Microbiota Axis Mood, Metabolism and Behaviour. Nat Rev Gastroenterol Hepatol (2017) 14 (2):69-70. doi: 10.1038/nrgastro.2016.200

41. Kelly JR, Clarke G, Cryan JF, Dinan TG. Brain-Gut-Microbiota Axis: Challenges for Translation in Psychiatry. Ann Epidemiol (2016) 26 (5):366-72. doi: 10.1016/j.annepidem.2016.02.008

42. Huang T-T, Lai J-B, Du Y-L, Xu Y, Ruan L-M, Hu S-H. Current Understanding of Gut Microbiota in Mood Disorders: An Update of Human Studies. Front Genet (2019) 10:98. doi: 10.3389/fgene.2019.00098

43. Naseribafrouei A, Hestad K, Avershina E, Sekelja M, Linløkken A, Wilson R, et al. Correlation Between the Human Fecal Microbiota and Depression. Neurogastroenterol Motil (2014) 26(8):1155-62. doi: 10.1111/nmo.12378

44. Qiao Y, Wu M, Feng Y, Zhou Z, Chen L, Chen F. Alterations of Oral Microbiota Distinguish Children With Autism Spectrum Disorders From Healthy Controls. Sci Rep (2018) 8(1):1-12. doi: 10.1038/s41598-01819982-y

45. Ballabh P, Braun A, Nedergaard M. The Blood-Brain Barrier: An Overview: Structure, Regulation, and Clinical Implications. Neurobiol Dis (2004) 16 (1):1-13. doi: 10.1016/j.nbd.2003.12.016

46. Daneman R, Prat A. The Blood-Brain Barrier. Cold Spring Harb Perspect Biol (2015) 7(1):a020412-a. doi: 10.1101/cshperspect.a020412

47. JoÓ F. The Blood-Brain Barrier. Nature (1987) 329(6136):208doi: $10.1038 / 329208$ b0

48. Banks WA. The Blood-Brain Barrier as an Endocrine Tissue. Nat Rev Endocrinol (2019) 15(8):444-55. doi: 10.1038/s41574-019-0213-7

49. Banks WA, Reed MJ, Logsdon AF, Rhea EM, Erickson MA. Healthy Aging and the Blood-Brain Barrier. Nat Aging (2021) 1(3):243-54. doi: 10.1038/ s43587-021-00043-5

50. Finger CE, Moreno-Gonzalez I, Gutierrez A, Moruno-Manchon JF, McCullough LD. Age-Related Immune Alterations and Cerebrovascular Inflammation. Mental Health Weekly Digest (2021) 267. doi: 10.1038/ s41380-021-01361-1

51. Obermeier B, Daneman R, Ransohoff RM. Development, Maintenance and Disruption of the Blood-Brain Barrier. Nat Med (2013) 19(12):1584-96. doi: $10.1038 / \mathrm{nm} .3407$

52. Galea I. The Blood-Brain Barrier in Systemic Infection and Inflammation. Cell Mol Immunol (2021) 18(11):2489-501. doi: 10.1038/s41423-021-00757-x

53. PRR-Signaling Pathways: Learning From Microbial Tactics. Semin Immunol (2015) 27(2):75-84. doi: 10.1016/j.smim.2015.03.009 
54. Skaper SD, Facci L, Zusso M, Giusti P. An Inflammation-Centric View of Neurological Disease: Beyond the Neuron. Front Cell Neurosci (2018) 12:72. doi: $10.3389 /$ fncel.2018.00072

55. Harrington M. For Lack of Gut Microbes, the Blood-Brain Barrier 'Leaks'. Lab Anim (NY) (2015) 44(1):6-. doi: 10.1038/laban.682

56. Braniste V, Al-Asmakh M, Kowal C, Anuar F, Abbaspour A, Tóth M, et al. The Gut Microbiota Influences Blood-Brain Barrier Permeability in Mice. Sci Trans Med (2014) 6(263):263ra158-263ra158. doi: 10.1126/ scitranslmed.3009759

57. Aho VT, Houser MC, Pereira PA, Chang J, Rudi K, Paulin L, et al. Relationships of Gut Microbiota, Short-Chain Fatty Acids, Inflammation, and the Gut Barrier in Parkinson's Disease. Mol Neurodegeneration (2021) 16(1):1-14. doi: 10.1186/s13024-021-00427-6

58. Miller SI, Ernst RK, Bader MW. LPS, TLR4 and Infectious Disease Diversity. Nat Rev Microbiol (2005) 3(1):36-46. doi: 10.1038/nrmicro1068

59. Wendeln A-C, Degenhardt K, Kaurani L, Gertig M, Ulas T, Jain G, et al. Innate Immune Memory in the Brain Shapes Neurological Disease Hallmarks. Nature (2018) 556(7701):332-8. doi: 10.1038/s41586-0180023-4

60. Bach Knudsen KE. Microbial Degradation of Whole-Grain Complex Carbohydrates and Impact on Short-Chain Fatty Acids and Health. Adv Nutr (2015) 6(2):206-13. doi: 10.3945/an.114.007450

61. Volmar C-H, Wahlestedt C. Histone Deacetylases (HDACs) and Brain Function. Neuroepigenetics (2015) 1:20-7. doi: 10.1016/j.nepig.2014.10.002

62. Chen G, Huang B, Fu S, Li B, Ran X, He D, et al. G Protein-Coupled Receptor 109A and Host Microbiota Modulate Intestinal Epithelial Integrity During Sepsis. Front Immunol (2018) 9:2079. doi: 10.3389/fimmu.2018.02079

63. Dalile B, Vervliet B, Bergonzelli G, Verbeke K, Van Oudenhove L. ColonDelivered Short-Chain Fatty Acids Attenuate the Cortisol Response to Psychosocial Stress in Healthy Men: A Randomized, Placebo-Controlled Trial. Neuropsychopharmacology (2020) 45(13):2257-66. doi: 10.1038/ s41386-020-0732-x

64. Romano KA, Vivas EI, Amador-Noguez D, Rey FE. Intestinal Microbiota Composition Modulates Choline Bioavailability From Diet and Accumulation of the Proatherogenic Metabolite Trimethylamine-N-Oxide. MBIO (2015) 6(2):e02481-e. doi: 10.1128/mBio.02481-14

65. Del Rio D, Zimetti F, Caffarra P, Tassotti M, Bernini F, Brighenti F, et al. The Gut Microbial Metabolite Trimethylamine-N-Oxide is Present in Human Cerebrospinal Fluid. Nutrients (2017) 9(10):1053. doi: 10.1128/mBio.02481-14

66. Vogt NM, Romano KA, Darst BF, Engelman CD, Johnson SC, Carlsson CM, et al. The Gut Microbiota-Derived Metabolite Trimethylamine N-Oxide is Elevated in Alzheimer's Disease. Alzheimer's Res Ther (2018) 10(1):1-8. doi: 10.1186/s13195-018-0451-2

67. Heiss CN, Olofsson LE. The Role of the Gut Microbiota in Development, Function and Disorders of the Central Nervous System and the Enteric Nervous System. J Neuroendocrinol (2019) 31(5):e12684-n/a. doi: 10.1111/jne.12684

68. Frankiensztajn LM, Elliott E, Koren O. The Microbiota and the Hypothalamus-Pituitary-Adrenocortical (HPA) Axis, Implications for Anxiety and Stress Disorders. Curr Opin Neurobiol (2020) 62:76-82. doi: $10.1016 /$ j.conb.2019.12.003

69. Sharon G, Sampson TR, Geschwind DH, Mazmanian SK. The Central Nervous System and the Gut Microbiome. Cell (2016) 167(4):915-32. doi: 10.1016/j.cell.2016.10.027

70. Kaelberer MM, Buchanan KL, Klein ME, Barth BB, Montoya MM, Shen X, et al. A Gut-Brain Neural Circuit for Nutrient Sensory Transduction. Science (2018) 361(6408):1219. doi: 10.1126/science.aat5236

71. Smith PM, Howitt MR, Panikov N, Michaud M, Gallini CA, Bohlooly $-\mathrm{M}$, et al. The Microbial Metabolites, Short-Chain Fatty Acids, Regulate Colonic Treg Cell Homeostasis. Sci (American Assoc Advancement Science) (2013) 341(6145):569-73. doi: 10.1126/science.1241165

72. Honda K, Littman DR. The Microbiota in Adaptive Immune Homeostasis and Disease. Nature (2016) 535(7610):75-84. doi: 10.1038/nature18848

73. Sun M, He C, Cong Y, Liu Z. Regulatory Immune Cells in Regulation of Intestinal Inflammatory Response to Microbiota. Mucosal Immunol (2015) 8 (5):969-78. doi: 10.1038/mi.2015.49

74. Zheng D, Liwinski T, Elinav E. Interaction Between Microbiota and Immunity in Health and Disease. Cell Res (2020) 30(6):492-506. doi: 10.1038/s41422-020-0332-7
75. Huang F, Wu X. Brain Neurotransmitter Modulation by Gut Microbiota in Anxiety and Depression. Front Cell Dev Biol (2021) 9:649103. doi: 10.3389/ fcell.2021.649103

76. Ashwini O, Chunyan C, Chien-Hung Y, Wolf-Julian N, James G, Harith A, et al. Neural Signatures of Hyperdirect Pathway Activity in Parkinson's Disease. Nat Commun (2021) 12(1):5185-. doi: 10.1038/s41467-021-25366-0

77. Gagliani N, Palm NW, de Zoete MR, Flavell RA. Inflammasomes and Intestinal Homeostasis: Regulating and Connecting Infection, Inflammation and the Microbiota. Int Immunol (2014) 26(9):495-9. doi: 10.1093/intimm/dxu066

78. Young JJ, Bruno D, Pomara N. A Review of the Relationship Between Proinflammatory Cytokines and Major Depressive Disorder. J Affect Disord (2014) 169:15-20. doi: 10.1016/j.jad.2014.07.032

79. Inoue $M$, Shinohara ML. The Role of Interferon- $\beta$ in the Treatment of Multiple Sclerosis and Experimental Autoimmune Encephalomyelitis-in the Perspective of Inflammasomes. Immunology (2013) 139(1):11-8. doi: 10.1111/imm.12081

80. Giles EM, Stagg AJ. Type 1 Interferon in the Human Intestine-a CoOrdinator of the Immune Response to the Microbiota. Inflamm Bowel Dis (2017) 23(4):524-33. doi: 10.1097/MIB.0000000000001078

81. Kawashima T, Kosaka A, Yan H, Guo Z, Uchiyama R, Fukui R, et al. DoubleStranded RNA of Intestinal Commensal But Not Pathogenic Bacteria Triggers Production of Protective Interferon- $\beta$. Immunity (2013) 38 (6):1187-97. doi: 10.1016/j.immuni.2013.02.024

82. Jang S, Lim S, Jeong J, Jang H, Lee H, Han M, et al. Gastrointestinal Inflammation by Gut Microbiota Disturbance Induces Memory Impairment in Mice. Mucosal Immunol (2018) 11(2):369-79. doi: 10.1038/mi.2017.49

83. Rogers GB, Keating DJ, Young RL, Wong ML, Licinio J, Wesselingh S. From Gut Dysbiosis to Altered Brain Function and Mental Illness: Mechanisms and Pathways. Mol Psychiatr (2016) 21(6):738-48. doi: 10.1038/mp.2016.50

84. Cao Y, Mezzenga R. Food Protein Amyloid Fibrils: Origin, Structure, Formation, Characterization, Applications and Health Implications. Adv Colloid Interface Sci (2019) 269:334-56. doi: 10.1016/j.cis.2019.05.002

85. Ciminelli BM, Menduti G, Benussi L, Ghidoni R, Binetti G, Squitti R, et al. Polymorphic Genetic Markers of the GABA Catabolism Pathway in Alzheimer's Disease. J Alzheimer's Dis (2020) Preprint):1-11. doi: 10.3233/ JAD-200429

86. Auger ML, Meccia J, Phillips AG, Floresco SB. Amelioration of Cognitive Impairments Induced by GABA Hypofunction in the Male Rat Prefrontal Cortex by Direct and Indirect Dopamine D1 Agonists SKF-81297 and DGovadine. Neuropharmacology (2020) 162:107844. doi: 10.1016/ j.neuropharm.2019.107844

87. Vogt NM, Kerby RL, Dill-McFarland KA, Harding SJ, Merluzzi AP, Johnson SC, et al. Gut Microbiome Alterations in Alzheimer's Disease. Sci Rep (2017) $7(1): 1-11$.

88. Zhuang Z-Q, Shen L-L, Li W-W, Fu X, Zeng F, Gui L, et al. Gut Microbiota is Altered in Patients With Alzheimer's Disease. J Alzheimer's Dis (2018) 63 (4):1337-46. doi: 10.3233/JAD-180176

89. Ling Z, Zhu M, Liu X, Shao L, Cheng Y, Yan X, et al. Fecal Fungal Dysbiosis in Chinese Patients With Alzheimer's Disease. Front Cell Dev Biol (2020) 8:631460. doi: $10.3389 /$ fcell.2020.631460

90. Nuzum ND, Loughman A, Szymlek-Gay EA, Hendy A, Teo W-P, Macpherson H. Gut Microbiota Differences Between Healthy Older Adults and Individuals With Parkinson's Disease: A Systematic Review. Neurosci Biobehav Rev (2020) 112:227-41. doi: 10.1016/j.neubiorev.2020.02.003

91. Christensen LFB, Jensen KF, Nielsen J, Vad BS, Christiansen G, Otzen DE. Reducing the Amyloidogenicity of Functional Amyloid Protein FapC Increases its Ability to Inhibit $\alpha$-Synuclein Fibrillation. ACS Omega (2019) 4(2):4029-39. doi: 10.1021/acsomega. 8 b03590

92. Sampson TR, Challis C, Jain N, Moiseyenko A, Ladinsky MS, Shastri GG, et al. A Gut Bacterial Amyloid Promotes $\alpha$-Synuclein Aggregation and Motor Impairment in Mice. Elife (2020) 9:e53111. doi: 10.7554/ eLife. 53111

93. Hopfner F, Künstner A, Müller SH, Künzel S, Zeuner KE, Margraf NG, et al. Gut Microbiota in Parkinson Disease in a Northern German Cohort. Brain Res (2017) 1667:41-5. doi: 10.1016/j.brainres.2017.04.019

94. Hasegawa S, Goto S, Tsuji H, Okuno T, Asahara T, Nomoto K, et al. Intestinal Dysbiosis and Lowered Serum Lipopolysaccharide-Binding 
Protein in Parkinson's Disease. PloS One (2015) 10(11):e0142164. doi: 10.1371/journal.pone.0142164

95. Scheperjans F, Aho V, Pereira PA, Koskinen K, Paulin L, Pekkonen E, et al. Gut Microbiota are Related to Parkinson's Disease and Clinical Phenotype. Movement Disord (2015) 30(3):350-8. doi: 10.1002/mds.26069

96. Fujita K, Seike T, Yutsudo N, Ohno M, Yamada H, Yamaguchi H, et al. Hydrogen in Drinking Water Reduces Dopaminergic Neuronal Loss in the 1-Methyl-4-Phenyl-1, 2, 3, 6-Tetrahydropyridine Mouse Model of Parkinson's Disease. PloS One (2009) 4(9):e7247. doi: 10.1371/ journal.pone. 0007247

97. Yoritaka A, Takanashi M, Hirayama M, Nakahara T, Ohta S, Hattori N. Pilot Study of H2 Therapy in Parkinson's Disease: A Randomized Double-Blind Placebo-Controlled Trial. Movement Disord (2013) 28(6):836-9. doi: 10.1002/mds. 25375

98. Guo Q, Yin X, Qiao M, Jia Y, Chen D, Shao J, et al. Hydrogen-Rich Water Ameliorates Autistic-Like Behavioral Abnormalities in Valproic AcidTreated Adolescent Mice Offspring. Front Behav Neurosci (2018) 12:170. doi: 10.3389/fnbeh.2018.00170

99. Kong G, Lê Cao K-A, Judd LM, Li S, Renoir T, Hannan AJ. Microbiome Profiling Reveals Gut Dysbiosis in a Transgenic Mouse Model of Huntington's Disease. Neurobiol Dis (2020) 135:104268. doi: 10.1016/ j.nbd.2018.09.001

100. Radulescu CI, Garcia-Miralles M, Sidik H, Bardile CF, Yusof NABM, Lee HU, et al. Reprint of: Manipulation of Microbiota Reveals Altered Callosal Myelination and White Matter Plasticity in a Model of Huntington Disease. Neurobiol Dis (2020) 135:104744. doi: 10.1016/ j.nbd.2020.104744

101. Miyake S, Kim S, Suda W, Oshima K, Nakamura M, Matsuoka T, et al. Dysbiosis in the Gut Microbiota of Patients With Multiple Sclerosis, With a Striking Depletion of Species Belonging to Clostridia XIVa and IV Clusters. PloS One (2015) 10(9):e0137429. doi: 10.1371/journal.pone.0137429

102. Cosorich I, Dalla-Costa G, Sorini C, Ferrarese R, Messina MJ, Dolpady J, et al. High Frequency of Intestinal TH17 Cells Correlates With Microbiota Alterations and Disease Activity in Multiple Sclerosis. Sci Adv (2017) 3(7): e1700492. doi: 10.1126/sciadv.1700492

103. Chen J, Chia N, Kalari KR, Yao JZ, Novotna M, Soldan MMP, et al. Multiple Sclerosis Patients Have a Distinct Gut Microbiota Compared to Healthy Controls. Sci Rep (2016) 6(1):1-10. doi: 10.1038/srep28484

104. Seshadri S, Wolf PA. Lifetime Risk of Stroke and Dementia: Current Concepts, and Estimates From the Framingham Study. Lancet Neurol (2007) 6(12):1106-14. doi: 10.1016/S1474-4422(07)70291-0

105. Braak H, Braak E. Neuropathological Stageing of Alzheimer-Related Changes. Acta Neuropathol (1991) 82(4):239-59. doi: 10.1007/ BF00308809

106. Tiraboschi P, Hansen L, Thal L, Corey-Bloom J. The Importance of Neuritic Plaques and Tangles to the Development and Evolution of AD. Neurology (2004) 62(11):1984-9. doi: 10.1212/01.WNL.0000129697.01779.0A

107. Jack JCR, Wiste HJ, Weigand SD, Knopman DS, Mielke MM, Vemuri P, et al. Different Definitions of Neurodegeneration Produce Similar Amyloid/ Neurodegeneration Biomarker Group Findings. Brain (2015) 138(Pt 12):3747-59. doi: 10.1093/brain/awv283

108. Uematsu M, Nakamura A, Ebashi M, Hirokawa K, Takahashi R, Uchihara T. Brainstem Tau Pathology in Alzheimer's Disease is Characterized by Increase of Three Repeat Tau and Independent of Amyloid $\beta$. Acta Neuropathol Commun (2018) 6(1):1-. doi: 10.1186/s40478-017-0501-1

109. Frisoni GB, Altomare D, Thal DR, Ribaldi F, van der Kant R, Ossenkoppele $\mathrm{R}$, et al. The Probabilistic Model of Alzheimer Disease: The Amyloid Hypothesis Revised. Nat Rev Neurosci (2021) 23(1):53-66. doi: 10.1038/ s41583-021-00533-w

110. Hampel H, Hardy J, Blennow K, Chen C, Perry G, Kim SH, et al. The Amyloid- $\beta$ Pathway in Alzheimer's Disease. Mol Psychiatry (2021) 1-23. doi: 10.1038/s41380-021-01249-0

111. Long JM, Holtzman DM. Alzheimer Disease: An Update on Pathobiology and Treatment Strategies. Cell (2019) 179(2):312-39. doi: 10.1016/ j.cell.2019.09.001

112. Kodamullil AT, Zekri F, Sood M, Hengerer B, Canard L, McHale D, et al. Trial Watch: Tracing Investment in Drug Development for Alzheimer Disease. Nat Rev Drug Discov (2017) 16(12):819.doi: 10.1038/nrd.2017.169
113. Tiihonen K, Ouwehand AC, Rautonen N. Human Intestinal Microbiota and Healthy Ageing. Ageing Res Rev (2009) 9(2):107-16. doi: 10.1016/ j.arr.2009.10.004

114. Marizzoni M, Cattaneo A, Mirabelli P, Luongo D, Mombelli E, Salvatore M, et al. Identification of Clinical Phenotypes of Alzheimer's Disease Through the Gut Microbiota. In: 2020 Alzheimer's Association International Conference. Geneva, Switzerland: ALZ. (2020).

115. Bäuerl C, Collado MC, Diaz Cuevas A, Viña J, Pérez Martínez G. Shifts in Gut Microbiota Composition in an APP/PSS 1 Transgenic Mouse Model of Alzheimer's Disease During Lifespan. Valencia, Spain: Wiley Online Library (2018).

116. Minter MR, Zhang C, Leone V, Ringus DL, Zhang X, Oyler-Castrillo P, et al. Antibiotic-Induced Perturbations in Gut Microbial Diversity Influences Neuro-Inflammation and Amyloidosis in a Murine Model of Alzheimer's Disease. Sci REP-UK (2016) 6(1):30028-. doi: 10.1038/srep30028

117. Minter MR, Hinterleitner R, Meisel M, Zhang C, Leone V, Zhang X, et al. Antibiotic-Induced Perturbations in Microbial Diversity During Post-Natal Development Alters Amyloid Pathology in an Aged APP(SWE)/PS1(Delta E9) Murine Model of Alzheimer's Disease. Sci Rep (2017) 7(1):10411. doi: 10.1038/s41598-017-11047-w

118. Harach T, Marungruang N, Duthilleul N, Cheatham V, Mc Coy K, Frisoni G, et al. Reduction of Abeta Amyloid Pathology in APPPS1 Transgenic Mice in the Absence of Gut Microbiota. Sci Rep (2017) 7(1):1-15. doi: 10.1038/ srep41802

119. Fujii Y, Nguyen TTT, Fujimura Y, Kameya N, Nakamura S, Arakawa K, et al. Fecal Metabolite of a Gnotobiotic Mouse Transplanted With Gut Microbiota From a Patient With Alzheimer's Disease. Biosci Biotechnol Biochem (2019) 83(11):2144-52. doi: 10.1080/09168451.2019.1644149

120. Kim M-S, Kim Y, Choi H, Kim W, Park S, Lee D, et al. Transfer of a Healthy Microbiota Reduces Amyloid and Tau Pathology in an Alzheimer's Disease Animal Model. Gut (2020) 69(2):283-94. doi: 10.1136/gutjnl-2018317431

121. Bate C, Veerhuis R, Eikelenboom P, Williarns A. Microglia Kill AmyloidBeta(1-42) Damaged Neurons by a CD14-Dependent Process. Neuroreport (2004) 15(9):1427-30. doi: 10.1097/01.wnr.0000132203.76836.16

122. Zanoni I, Ostuni R, Marek LR, Barresi S, Barbalat R, Barton GM, et al. CD14 Controls the LPS-Induced Endocytosis of Toll-Like Receptor 4. Cell (2011) 147(4):868-80. doi: 10.1016/j.cell.2011.09.051

123. Zhao Y, Jaber V, Lukiw WJ. Secretory Products of the Human GI Tract Microbiome and Their Potential Impact on Alzheimer's Disease (AD): Detection of Lipopolysaccharide (LPS) in AD Hippocampus. Front Cell Infect Microbiol (2017) 7:318. doi: 10.3389/fcimb.2017.00318

124. Andreadou EG, Katsipis G, Tsolaki M, Pantazaki AA. Involvement and Relationship of Bacterial Lipopolysaccharides and Cyclooxygenases Levels in Alzheimer's Disease and Mild Cognitive Impairment Patients. J Neuroimmunol (2021) 357:577561. doi: 10.1016/j.jneuroim.2021.577561

125. Zhao J, Bi W, Xiao S, Lan X, Cheng X, Zhang J, et al. Neuroinflammation Induced by Lipopolysaccharide Causes Cognitive Impairment in Mice. Sci Rep (2019) 9(1):1-12. doi: 10.1038/s41598-019-42286-8

126. Bassi GS, Kanashiro A, Santin FM, de Souza GE, Nobre MJ, Coimbra NC. Lipopolysaccharide-Induced Sickness Behaviour Evaluated in Different Models of Anxiety and Innate Fear in Rats. Basic Clin Pharmacol Toxicol (2012) 110(4):359-69. doi: 10.1111/j.1742-7843.2011.00824.x

127. Wolf AJ, Underhill DM. Peptidoglycan Recognition by the Innate Immune System. Nat Rev Immunol (2018) 18(4):243-54. doi: 10.1038/nri.2017.136

128. Arentsen T, Qian Y, Gkotzis S, Femenia T, Wang T, Udekwu K, et al. The Bacterial Peptidoglycan-Sensing Molecule Pglyrp2 Modulates Brain Development and Behavior. Mol Psychiatry (2017) 22(2):257-66. doi: 10.1038/mp.2016.182

129. Tetz G, Pinho M, Pritzkow S, Mendez N, Soto C, Tetz V. Bacterial DNA Promotes Tau Aggregation. Sci Rep (2020) 10(1):1-11. doi: 10.1038/s41598020-59364-x

130. Tetz G, Tetz V. Bacterial Extracellular DNA Promotes $\beta$-Amyloid Aggregation. Microorganisms (2021) 9(6):1301. doi: 10.3390/ microorganisms 9061301

131. Javed I, Zhang Z, Adamcik J, Andrikopoulos N, Li Y, Otzen DE, et al. Accelerated Amyloid Beta Pathogenesis by Bacterial Amyloid FapC. Advanced Sci (2020) 7(18):2001299. doi: 10.1002/advs.202001299 
132. Ho L, Ono K, Tsuji M, Mazzola P, Singh R, Pasinetti GM. Protective Roles of Intestinal Microbiota Derived Short Chain Fatty Acids in Alzheimer's Disease-Type Beta-Amyloid Neuropathological Mechanisms. Expert Rev Neurother (2018) 18(1):83-90. doi: 10.1080/ 14737175.2018.1400909

133. Zhang L, Wang Y, Xiayu X, Shi C, Chen W, Song N, et al. Altered Gut Microbiota in a Mouse Model of Alzheimer's Disease. J Alzheimer's Dis (2017) 60(4):1241-57. doi: 10.3233/JAD-170020

134. Zheng J, Zheng S-J, Cai W-J, Yu L, Yuan B-F, Feng Y-Q. Stable Isotope Labeling Combined With Liquid Chromatography-Tandem Mass Spectrometry for Comprehensive Analysis of Short-Chain Fatty Acids. Anal Chimica Acta (2019) 1070:51-9. doi: 10.1016/j.aca.2019.04.021

135. Sun J, Yuan B, Wu Y, Gong Y, Guo W, Fu S, et al. Sodium Butyrate Protects N2a Cells Against A $\beta$ Toxicity In Vitro. Mediators Inflamm (2020) 2020:7605160-9. doi: 10.1155/2020/7605160

136. Grant SM, DeMorrow S. Bile Acid Signaling in Neurodegenerative and Neurological Disorders. Int J Mol Sci (2020) 21(17):5982. doi: 10.3390/ ijms21175982

137. Zwicker BL, Agellon LB. Transport and Biological Activities of Bile Acids. Int J Biochem Cell Biol (2013) 45(7):1389-98. doi: 10.1016/j.biocel. 2013.04.012

138. Nho K, Kueider-Paisley A, MahmoudianDehkordi S, Arnold M, Risacher SL, Louie G, et al. Altered Bile Acid Profile in Mild Cognitive Impairment and Alzheimer's Disease: Relationship to Neuroimaging and CSF Biomarkers. Alzheimer's Dementia (2019) 15(2):232-44. doi: 10.1016/j.jalz.2018.08.012

139. Xu R, Wang Q. Towards Understanding Brain-Gut-Microbiome Connections in Alzheimer's Disease. BMC Syst Biol (2016) 10 (3):277-85. doi: 10.1186/s12918-016-0307-y

140. Yang D-S, Yip CM, Huang TJ, Chakrabartty A, Fraser PE. Manipulating the Amyloid- $\beta$ Aggregation Pathway With Chemical Chaperones. J Biol Chem (1999) 274(46):32970-4. doi: 10.1074/jbc.274.46.32970

141. Li D, Ke Y, Zhan R, Liu C, Zhao M, Zeng A, et al. Trimethylamine-N-Oxide Promotes Brain Aging and Cognitive Impairment in Mice. Aging Cell (2018) 17(4):e12768. doi: 10.1111/acel.12768

142. Gao Q, Wang Y, Wang X, Fu S, Zhang X, Wang R-T, et al. Decreased Levels of Circulating Trimethylamine N-Oxide Alleviate Cognitive and Pathological Deterioration in Transgenic Mice: A Potential Therapeutic Approach for Alzheimer's Disease. Aging (Albany NY) (2019) 11(19):8642. doi: 10.18632/aging.102352

143. Marras C, Beck J, Bower J, Roberts E, Ritz B, Ross G, et al. Prevalence of Parkinson's Disease Across North America. NPJ Parkinson's Dis (2018) 4 (1):1-7. doi: 10.1038/s41531-018-0058-0

144. Lee A, Gilbert RM. Epidemiology of Parkinson Disease. Neurol Clinics (2016) 34(4):955-65. doi: 10.1016/j.ncl.2016.06.012

145. Fyfe I. Movement Disorders: Comparison of Cognitive Impairment in Parkinson Disease and Essential Tremor. Nat Rev Neurol (2017) 13 (5):260-. doi: 10.1038/nrneurol.2017.40

146. Hayes MT. Parkinson's Disease and Parkinsonism. Am J Med (2019) 132 (7):802-7. doi: 10.1016/j.amjmed.2019.03.001

147. Simon DK, Tanner CM, Brundin P. Parkinson Disease Epidemiology, Pathology, Genetics, and Pathophysiology. Clinics Geriatr Med (2020) 36 (1):1-12. doi: 10.1016/j.cger.2019.08.002

148. Braak H, Del Tredici K, Rüb U, De Vos RA, Steur ENJ, Braak E. Staging of Brain Pathology Related to Sporadic Parkinson's Disease. Neurobiol Aging (2003) 24(2):197-211. doi: 10.1016/S0197-4580(02)00065-9

149. Forsyth CB, Shannon KM, Kordower JH, Voigt RM, Shaikh M, Jaglin JA, et al. Increased Intestinal Permeability Correlates With Sigmoid Mucosa Alpha-Synuclein Staining and Endotoxin Exposure Markers in Early Parkinson's Disease. PloS One (2011) 6(12):e28032. doi: 10.1371/ journal.pone.0028032

150. Tan AH, Mahadeva S, Thalha AM, Gibson PR, Kiew CK, Yeat CM, et al. Small Intestinal Bacterial Overgrowth in Parkinson's Disease. Parkinsonism Relat Disord (2014) 20(5):535-40. doi: 10.1016/j.parkreldis.2014.02.019

151. Sampson TR, Debelius JW, Thron T, Janssen S, Shastri GG, Ilhan ZE, et al. Gut Microbiota Regulate Motor Deficits and Neuroinflammation in a Model of Parkinson's Disease. Cell (2016) 167(6):1469-80. e12.

152. Huang $\mathrm{H}, \mathrm{Xu} \mathrm{H}$, Luo Q, He J, Li M, Chen H, et al. Fecal Microbiota Transplantation to Treat Parkinson's Disease With Constipation: A Case
Report. Medicine (Baltimore) (2019) 98(26):e16163. doi: 10.1097/ MD.0000000000016163

153. Hu Q, Wang G. Mitochondrial Dysfunction in Parkinson's Disease. Trans Neurodegeneration (2016) 5(1):1-8. doi: 10.1186/s40035-016-0060-6

154. Hernández-Romero MDC, Argüelles S, Villarán RF, De Pablos RM, Delgado-Cortés MJ, Santiago M, et al. Simvastatin Prevents the Inflammatory Process and the Dopaminergic Degeneration Induced by the Intranigral Injection of Lipopolysaccharide. J Neurochem (2008) 105(2):44559. doi: 10.1111/j.1471-4159.2007.05148.x

155. Deng I, Corrigan F, Zhai G, Zhou X-F, Bobrovskaya L. Lipopolysaccharide Animal Models of Parkinson's Disease: Recent Progress and Relevance to Clinical Disease. Brain Behav Immunity Health (2020) 4:100060. doi: 10.1016/j.bbih.2020.100060

156. Goldman SM, Kamel F, Ross GW, Jewell SA, Marras C, Hoppin JA, et al. Peptidoglycan Recognition Protein Genes and Risk of Parkinson's Disease. Movement Disord (2014) 29(9):1171-80. doi: 10.1002/mds.25895

157. Manole E, Dumitrescu L, Niculițe C, Popescu BO, Ceafalan LC. Potential Roles of Functional Bacterial Amyloid Proteins, Bacterial Biosurfactants and Other Putative Gut Microbiota Products in the Etiopathogeny of Parkinson's Disease. Biocell (2021) 45(1):1. doi: 10.32604/biocell.2021.013452

158. Shin C, Lim Y, Lim H, Ahn TB. Plasma Short-Chain Fatty Acids in Patients With Parkinson's Disease. Movement Disord (2020) 35(6):1021-7. doi: $10.1002 / \mathrm{mds} .28016$

159. Sankowski B, Księżarczyk K, Raćkowska E, Szlufik S, Koziorowski D, Giebułtowicz J. Higher Cerebrospinal Fluid to Plasma Ratio of P-Cresol Sulfate and Indoxyl Sulfate in Patients With Parkinson's Disease. Clinica Chimica Acta (2020) 501:165-73. doi: 10.1016/j.cca.2019.10.038

160. Chung SJ, Rim JH, Ji D, Lee S, Yoo HS, Jung JH, et al. Gut MicrobiotaDerived Metabolite Trimethylamine N-Oxide as a Biomarker in Early Parkinson's Disease. Nutrition (2021) 83:111090. doi: 10.1016/ j.nut.2020.111090

161. Ostojic SM. Inadequate Production of $\mathrm{H} 2$ by Gut Microbiota and Parkinson Disease. Trends Endocrinol Metab (2018) 29(5):286-8. doi: 10.1016/ j.tem.2018.02.006

162. Suzuki A, Ito M, Hamaguchi T, Mori H, Takeda $Y$, Baba R, et al. Quantification of Hydrogen Production by Intestinal Bacteria That are Specifically Dysregulated in Parkinson's Disease. PloS One (2018) 13(12): e0208313. doi: 10.1371/journal.pone.0208313

163. Sim M, Kim C-S, Shon W-J, Lee Y-K, Choi EY, Shin D-M. Hydrogen-Rich Water Reduces Inflammatory Responses and Prevents Apoptosis of Peripheral Blood Cells in Healthy Adults: A Randomized, Double-Blind, Controlled Trial. Sci Rep (2020) 10(1):1-10. doi: 10.1038/s41598-020-68930-2

164. Erkkinen MG, Kim M-O, Geschwind MD. Clinical Neurology and Epidemiology of the Major Neurodegenerative Diseases. Cold Spring Harbor Perspect Biol (2018) 10(4):a033118. doi: 10.1101/cshperspect. a033118

165. Gatto EM, Rojas NG, Persi G, Etcheverry JL, Cesarini ME, Perandones C. Huntington Disease: Advances in the Understanding of its Mechanisms. Clin Parkinsonism Relat Disord (2020) 3:100056. doi: 10.1016/j.prdoa. 2020.100056

166. Rosas HD, Salat DH, Lee SY, Zaleta AK, Pappu V, Fischl B, et al. Cerebral Cortex and the Clinical Expression of Huntington's Disease: Complexity and Heterogeneity. Brain (2008) 131(4):1057-68. doi: 10.1093/brain/awn025

167. Sun Y-M, Zhang Y-B, Wu Z-Y. Huntington's Disease: Relationship Between Phenotype and Genotype. Mol Neurobiol (2017) 54(1):342-8. doi: 10.1007/ s12035-015-9662-8

168. Wasser CI, Mercieca E-C, Kong G, Hannan AJ, McKeown SJ, GlikmannJohnston Y, et al. Gut Dysbiosis in Huntington's Disease: Associations Among Gut Microbiota, Cognitive Performance and Clinical Outcomes. Brain Commun (2020) 2(2):fcaa110. doi: 10.1093/braincomms/fcaal10

169. Du G, Dong W, Yang Q, Yu X, Ma J, Gu W, et al. Altered Gut Microbiota Related to Inflammatory Responses in Patients With Huntington's Disease. Front Immunol (2020) 11:603594. doi: 10.3389/fimmu.2020. 603594

170. Konjevod M, Perkovic MN, Sáiz J, Strac DS, Barbas C, Rojo D. Metabolomics Analysis of Microbiota-Gut-Brain Axis in Neurodegenerative and Psychiatric Diseases. J Pharm Biomed Anal (2020) 194:113681. doi: 10.1016/j.jpba.2020.113681 
171. Rosas HD, Doros G, Bhasin S, Thomas B, Gevorkian S, Malarick K, et al. A Systems-Level "Misunderstanding": The Plasma Metabolome in Huntington's Disease. Ann Clin Trans Neurol (2015) 2(7):756-68. doi: 10.1002/acn3.214

172. Vidal-Jordana A, Montalban X. Multiple Sclerosis: Epidemiologic, Clinical, and Therapeutic Aspects. Neuroimaging Clinics (2017) 27(2):195-204. doi: 10.1016/j.nic.2016.12.001

173. Miller DH, Leary SM. Primary-Progressive Multiple Sclerosis. Lancet Neurol (2007) 6(10):903-12. doi: 10.1016/S1474-4422(07)70243-0

174. Miller DH, Chard DT, Ciccarelli O. Clinically Isolated Syndromes. Lancet Neurol (2012) 11(2):157-69. doi: 10.1016/S1474-4422(11)70274-5

175. Goldenberg MM. Multiple Sclerosis Review. P T (2012) 37(3):175-84.

176. Schepici G, Silvestro S, Bramanti P, Mazzon E. The Gut Microbiota in Multiple Sclerosis: An Overview of Clinical Trials. Cell Transplant (2019) 28 (12):1507-27. doi: 10.1177/0963689719873890

177. Jangi S, Gandhi R, Cox LM, Li N, von Glehn F, Yan R, et al. Alterations of the Human Gut Microbiome in Multiple Sclerosis. Nat Commun (2016) 7 (1):12015. doi: 10.1038/ncomms 12015

178. Berer K, Gerdes LA, Cekanaviciute E, Jia X, Xiao L, Xia Z, et al. Gut Microbiota From Multiple Sclerosis Patients Enables Spontaneous Autoimmune Encephalomyelitis in Mice. Proc Natl Acad Sci (2017) 114 (40):10719-24. doi: 10.1073/pnas.1711233114

179. Cekanaviciute E, Yoo BB, Runia TF, Debelius JW, Singh S, Nelson CA, et al. Gut Bacteria From Multiple Sclerosis Patients Modulate Human T Cells and Exacerbate Symptoms in Mouse Models. Proc Natl Acad Sci (2017) 114 (40):10713-8. doi: 10.1073/pnas.1711235114

180. Borody T, Leis S, Campbell J, Torres M, Nowak A. Fecal Microbiota Transplantation (FMT) in Multiple Sclerosis (MS): 942. Off J Am Coll Gastroenterol ACG (2011) 106:S352. doi: 10.14309/00000434-201110002-00942

181. Makkawi S, Camara-Lemarroy C, Metz L. Fecal Microbiota Transplantation Associated With 10 Years of Stability in a Patient With SPMS. Neurol Neuroimmunol Neuroinflamm (2018) 5(3):e459. doi: 10.1212/ NXI.0000000000000459

182. Olsson T, Barcellos LF, Alfredsson L. Interactions Between Genetic, Lifestyle and Environmental Risk Factors for Multiple Sclerosis. Nat Rev Neurol (2017) 13(1):25-36. doi: 10.1038/nrneurol.2016.187

183. Amato MP, Derfuss T, Hemmer B, Liblau R, Montalban X, Soelberg Sørensen P, et al. Environmental Modifiable Risk Factors for Multiple Sclerosis: Report From the 2016 ECTRIMS Focused Workshop. Multiple Sclerosis J (2018) 24(5):590-603. doi: 10.1177/1352458516686847

184. Turnbaugh PJ, Hamady M, Yatsunenko T, Cantarel BL, Duncan A, Ley RE, et al. A Core Gut Microbiome in Obese and Lean Twins. nature (2009) 457 (7228):480-4. doi: 10.1038/nature07540

185. Munger KL, Levin LI, Hollis BW, Howard NS, Ascherio A. Serum 25Hydroxyvitamin D Levels and Risk of Multiple Sclerosis. Jama (2006) 296 (23):2832-8. doi: 10.1001/jama.296.23.2832

186. Riccio P, Rossano R, Larocca M, Trotta V, Mennella I, Vitaglione P, et al. Anti-Inflammatory Nutritional Intervention in Patients With RelapsingRemitting and Primary-Progressive Multiple Sclerosis: A Pilot Study. Exp Biol Med (2016) 241(6):620-35. doi: 10.1177/1535370215618462

187. Cignarella F, Cantoni C, Ghezzi L, Salter A, Dorsett Y, Chen L, et al. Intermittent Fasting Confers Protection in CNS Autoimmunity by Altering the Gut Microbiota. Cell Metab (2018) 27(6):1222-35. e6. doi: 10.1016/ j.cmet.2018.05.006

188. Liu P, Wu L, Peng G, Han Y, Tang R, Ge J, et al. Altered Microbiomes Distinguish Alzheimer's Disease From Amnestic Mild Cognitive Impairment and Health in a Chinese Cohort. Brain Behav Immun (2019) 80:633-43. doi: 10.1016/j.bbi.2019.05.008

189. Li B, He Y, Ma J, Huang P, Du J, Cao L, et al. Mild Cognitive Impairment has Similar Alterations as Alzheimer's Disease in Gut Microbiota. Alzheimer's Dementia (2019) 15(10):1357-66. doi: 10.1016/j.jalz.2019.07.002

190. Fang X, Zhou X, Miao Y, Han Y, Wei J, Chen T. Therapeutic Effect of GLP-1 Engineered Strain on Mice Model of Alzheimer's Disease and
Parkinson's Disease. AMB Expr (2020) 10(1):80-. doi: 10.1186/s13568020-01014-6

191. Bedarf JR, Hildebrand F, Coelho LP, Sunagawa S, Bahram M, Goeser F, et al. Functional Implications of Microbial and Viral Gut Metagenome Changes in Early Stage L-DOPA-Naïve Parkinson's Disease Patients. Genome Med (2017) 9(1):39-. doi: 10.1186/s13073-017-0428-y

192. Ou Z, Deng L, Lu Z, Wu F, Liu W, Huang D, et al. Protective Effects of Akkermansia Muciniphila on Cognitive Deficits and Amyloid Pathology in a Mouse Model of Alzheimer's Disease. Nutr Diabetes (2020) 10(1):12-. doi: 10.1038/s41387-020-0115-8

193. Hedrich H, Von Beust B, Bullock GR, Petrusz P. The Laboratory Mouse. San Diego: San Diego: Elsevier Science \& Technology (2012).

194. Cooper-Knock J, Kirby J, Ferraiuolo L, Heath PR, Rattray M, Shaw PJ. Gene Expression Profiling in Human Neurodegenerative Disease. Nat Rev Neurol (2012) 8(9):518-30. doi: 10.1038/nrneurol.2012.156

195. Perry VH, Newman TA, Cunningham C. The Impact of Systemic Infection on the Progression of Neurodegenerative Disease. Nat Rev Neurosci (2003) 4 (2):103-12. doi: $10.1038 /$ nrn 1032

196. Forman MS, Trojanowski JQ, Lee VMY. Neurodegenerative Diseases: A Decade of Discoveries Paves the Way for Therapeutic Breakthroughs. Nat Med (2004) 10(10):1055-63. doi: 10.1038/nm1113

197. Dawson TM, Golde TE, Lagier-Tourenne C. Animal Models of Neurodegenerative Diseases. Nat Neurosci (2018) 21(10):1370-9. doi: 10.1038/s41593-018-0236-8

198. Hetz C, Mollereau B. Disturbance of Endoplasmic Reticulum Proteostasis in Neurodegenerative Diseases. Nat Rev Neurosci (2014) 15(4):233-49. doi: $10.1038 / \mathrm{nrn} 3689$

199. Barnham KJ, Masters CL, Bush AI. Neurodegenerative Diseases and Oxidative Stress. Nat Rev Drug Discovery (2004) 3(3):205-14. doi: 10.1038/nrd1330

200. Dodiya HB, Forsyth CB, Voigt RM, Engen PA, Patel J, Shaikh M, et al. Chronic Stress-Induced Gut Dysfunction Exacerbates Parkinson's Disease Phenotype and Pathology in a Rotenone-Induced Mouse Model of Parkinson's Disease. Neurobiol Dis (2020) 135:104352. doi: 10.1016/ j.nbd.2018.12.012

201. Mat Taib CN, Mustapha M. MPTP-Induced Mouse Model of Parkinson's Disease: A Promising Direction of Therapeutic Strategies. Bosn J Basic Med Sci (2020) 21(4):422. doi: 10.17305/bjbms.2020.5181

202. Leite G, Pimentel M, Barlow GM, Chang C, Hosseini A, Wang J, et al. Age and the Aging Process Significantly Alter the Small Bowel Microbiome. Cell Rep (Cambridge) (2021) 36(13):109765-. doi: 10.1016/j.celrep.2021.109765

203. Mattson MP, Magnus T. Ageing and Neuronal Vulnerability. Nat Rev Neurosci (2006) 7(4):278-94. doi: 10.1038/nrn1886

204. McKinnon PJ. Maintaining Genome Stability in the Nervous System. Nat Neurosci (2013) 16(11):1523-9. doi: 10.1038/nn.3537

Conflict of Interest: The authors declare that the research was conducted in the absence of any commercial or financial relationships that could be construed as a potential conflict of interest.

Publisher's Note: All claims expressed in this article are solely those of the authors and do not necessarily represent those of their affiliated organizations, or those of the publisher, the editors and the reviewers. Any product that may be evaluated in this article, or claim that may be made by its manufacturer, is not guaranteed or endorsed by the publisher.

Copyright (c) 2022 Zhang, Chen, Wang, Xie, Liu, Yuan, Chai, Wang and Cheng. This is an open-access article distributed under the terms of the Creative Commons Attribution License (CC BY). The use, distribution or reproduction in other forums is permitted, provided the original author(s) and the copyright owner(s) are credited and that the original publication in this journal is cited, in accordance with accepted academic practice. No use, distribution or reproduction is permitted which does not comply with these terms. 